\title{
Diques máficos da Província Litorânea, Estado da Bahia: Estudo comparativo com Ilhéus-Olivença
}

\author{
João Pedro Moreno GOMES \& Angela Beatriz de MENEZES LEAL
}

Programa de Pós-graduação em Geologia, Instituto de Geociências, Universidade Federal da Bahia. Rua Barão de Jeremoabo, s/n, CEP 40170-290, Salvador, BA, Brasil (joaopmoreno@outlook.com, angelab@ufba.br).

\begin{abstract}
Resumo. Estudos comparativos de dados petrográficos, geoquímicos e geocronológicos de diques máficos permitem estabelecer relações entre diferentes enxames, seus processos de gênese e evolução magmática, contribuindo para a evolução geodinâmica de uma determinada região e a caracterização da natureza das fontes mantélicas de eventos extensionais. Os diques máficos de Ilhéus-Olivença, Salvador, Camacan e Itajú do Colônia, pertencentes a Província Litorânea $(\mathrm{PL})$, estão localizados no nordeste do Cráton do São Francisco, próximo à costa marítima da Bahia e encaixados em rochas granulíticas de cinturões orogênicos paleoproterozoicos. O enxame de Ilhéus-Olivença apresenta diques com espessuras medias de menos de $3 \mathrm{~m}$, com orientação preferencial E-W e hospedam enclaves rotacionados, com fluxo magmático direcionado de leste para oeste. A assembleia mineralógica essencial é composta por plagioclásio, piroxênios, olivina, hornblenda e minerais opacos, apresentando texturas intergranular, ofítica, porfirítica e subofítica, além de processos de alteração secundaria. São basaltos toleíticos de ambiente intraplaca, com leve enriquecimento em ETRL comparados com ETRP, mostrando uma fonte enriquecida do tipo E-MORB, com tendências próximas do manto primitivo. Quando comparado com os outros diques máficos da PL apresentam semelhanças quanto aos aspectos de campo, petrográficos e geoquímicos. A integração dos estudos geoquímicos com dados geocronológicos da literatura da PL revela que essas rochas fazem parte do mesmo evento extensional Toniano, provavelmente relacionado a uma mesma pluma mantélica.
\end{abstract}

Palavras-chave. geoquímica, petrografia, enxames de diques, magmatismo basáltico.

Abstract. COASTAL PROVINCE MAFIC DYKES, STATE OF BAHIA: COMPARATIVE STUdY WITH ILHÉUSOLIVENÇA. Comparative studies of petrographic, geochemical and geochronological data of mafic dykes allow establishing relationships among different swarms, their processes of genesis and magmatic evolution, contributing to the geodynamic evolution of a given region and the characterization of the nature of mantle sources of extensional events. The mafic dikes of Ilhéus-Olivença, Salvador, Camacan and Itajú do Colônia, belonging to the Coastal Province (PL), are located in the northeast of the Francisco Craton, close to the sea coast of Bahia and emplaced in granulitic rocks of paleoproterozoic orogenic belts. The Ilhéus-Olivença swarm has dikes with average thickness of less than $3 \mathrm{~m}$, with preferential E-W orientation and host rotated enclave structures, with magmatic flow directed from east to west. The essential mineralogical assembly is composed of plagioclase, pyroxenes, olivine, hornblende and opaque minerals, presenting intergranular, ophitic, porphyritic and subophitic textures, besides secondary alteration processes. They are tholeiitic basalts of intra-plate setting, with slight enrichment in ETRL compared to ETRP, showing an E-MORB source, with samples close to the primitive mantle. When compared with the other mafic dykes of $\mathrm{PL}$, they have similarities in terms of field, petrographic and geochemical aspects. The integration of geochemical studies with geochronological data from the PL literature reveals that these rocks are part of the same extensional Tonian event, probably related to the same mantle plume.

Keywords. geochemistry, petrography, dykes swarms, basaltic magmatism. 


\section{Introdução}

Diques máficos são expressões do magmatismo de composição basáltica associadas a processos de extensão crustal que ocorrem em várias partes do planeta. São sensíveis indicadores do contexto geodinâmico da Terra, visto que fornecem informações sobre fontes mantélicas e sua evolução, a configuração da tectônica de placas, assim como na reconstrução de paleocontinentes e campos de paleoesforço locais e regionais (Corrêa-Gomes et al., 1996; Menezes Leal et al., 2012).

No estado da Bahia, os diques máficos em enxames foram inicialmente divididos por Corrêa-Gomes et al. (1996) em províncias filonianas e, posteriormente por Menezes Leal et al. (2012) em seis províncias e quatro ocorrências. As províncias de diques máficos conhecidas no Estado da Bahia são: (i) Uauá-Caracatá, (ii) Salvador, (iii) Chapada Diamantina-Paramirim, (iv) Litorânea, (v) Caraíba-Curaçá e, (vi) ItabunaItajú do Colônia, enquanto as ocorrências de diques máficos são expressões geográficas menores que apresentam dados de campo, petrográficos, geoquímicos e geocronológicos pouco detalhados. Na Bahia as ocorrências conhecidas são: (i) Feira de Santana-Lamarão, (ii) José do Jacuípe-Aroeira, (iii) Juazeiro-Salobrinho e, (iv) Coronel João Sá.

Este trabalho aborda o estudo petrográfico e geoquímico do enxame de diques máficos da região de Ilhéus-Olivença, no sul do estado da Bahia, localizado a nordeste do Cráton do São Francisco, encaixado em rochas granulíticas e pertencente à Província Litorânea (PL). Adicionalmente, são incorporados a esse estudo dados petrográficos, geoquímicos e geocronológicos dos diques máficos de Salvador, Camacane Itajú do Colônia (e.g. Tanner deOliveira, 1989; Moraes Brito, 1992; Santos, 2010; Cruz, 2013; Vieira, 2016; Pinheiro Amorim, 2017; Silva, 2018) objetivando o estudo comparativo entre os corpos filonianos da PL, visando contribuir com novas informações para o entendimento dos processos envolvidos na gênese dessas rochas.

Dados geocronológicos obtidos pelo métodoAr-Ar embiotita(D'Agrella Filho etal., 1989; Renne et al., 1990) na região de Ilhéus-Olivença, forneceram idades isotópicas de 1077 \pm 25 Ma e

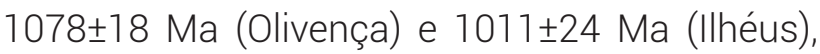
e para os diques máficos de Salvador, idade de $1021 \pm 8 \mathrm{Ma}$, pelo mesmo método. No entanto, Evans et al. (2015) utilizando o método U-Pb em badeleítas obtiveram idade de 926,1 \pm 4,6 Ma para os diques de Ilhéus e 918,2 \pm 6,7 Ma para os de Olivença. Pinheiro Amorim (2017) obteve a partir do método Rb-Sr idade de $1387 \pm 390 \mathrm{Ma}$ para os diques de Itajú do Colônia. Considerando o erro da datação, a idade pode corresponder aquelas relacionadas a aproximadamente 1000 Ma. Para os diques máficos de Camacan não temos dados geocronológicos na literatura. Considerando as idades obtidas para os diques máficos da Província Litorânea, podemos sugerir que esses corpos são coevos e podem estar associados ao mesmo evento de magmatismo basáltico intraplaca de idade esteniana/toniana.

Corrêa-Gomes (2000) definiu que os diques máficos de Ilhéus-Olivença são parte de um grande enxame com padrão radial relacionado ao momento pré-drift de domeamento litosférico durante o evento de separação dos cratons do São Francisco e Congo em 1,0 Ga. Chaves et al. (2018) sugere que esses corpos máficos apresentam semelhanças petrográficas, geoquímicas e geocronológicas com os enxames em Pedro Lessa e Formiga, em Minas Gerais, e à sequência basáltica Gangila e aos enxames de Ebolowa, Sembe-Ouesso e Comba na África, sendo todos eles expressões de uma Large Igneous Province (LIP) denominada de Bahia-Gangila originada de um evento de superpluma entre 900-920 Ma que cobriu uma área de aproximadamente 1.500.000 $\mathrm{km}^{2}$ entre o Brasil e África, e aponta para um evento geotectônico extensional de tentativa de ruptura litosférica do supercontinente Rodínia.

\section{2 Área de estudo, materiais e métodos}

\subsection{Localização e contexto geológico regional da área}

A área de estudo está na mesorregião sul do estado da Bahia e compreende a orla da sede da cidade de Ilhéus, com os principais afloramentos no morro do Pernambuco, e mais ao sul a orla da vila de Olivença. O acesso a área de estudo ao sul 
a partir da capital Salvador é feito através da BR324, passando para a BR-101 no entroncamento após Amélia Rodrigues seguindo $341 \mathrm{~km}$ até Itabuna, de onde é possível ter acesso a Ilhéus após $30 \mathrm{~km}$ pela BR-415 (Fig. 1).

Os corpos máficos filonianos de IlhéusOlivença estão inseridos no contexto geotectônico do Cráton do São Francisco (CSF) na porção sul do Cinturão Itabuna-Salvador-Curaçá (CISC). o CSF representa o núcleo cristalino localizado em grande parte dos estados da Bahia e de Minas Gerais, que não participou dos processos orogênicos do Fanerozoico, atuando como antepaís durante o ciclo orogenético Brasiliano. As rochas arqueanas e paleoproterozoicas do seu substrato foram submetidas ao metamorfismo variando de fácies xisto verde até granulito durante a orogenia paleoproterozoica, no qual quatro blocos arqueanos (Gavião, Serrinha,
Jequié e Itabuna-Salvador-Curaçá) colidiram e formaram o Cinturão Itabuna-Salvador-Curaçá (CISC) de orientação aproximada N-S, porém devido ao processo erosivo somente as rochas da raiz granulítica desse cinturão estão preservadas em afloramentos (Barbosa \& Sabaté, 2003).

A parte sul do Cinturão Itabuna-SalvadorCuraçá é composta em sua maioria por granulitos tonalítico-trondhjemíticos, granulitos monzoníticos e monzodioríticos, e de forma mais restrita os granulitos básicos e granulitos paraderivados. Esses litotipos foram penetrados por corpos sieníticos, rochas dunito-peridotíticas e diques máficos, sendo esses últimos objetos desse trabalho (Fig. 2). Os diques máficos que ocorrem em Salvador estão encaixados nas rochas granulíticas do cinturão SalvadorEsplanada-Boquim (Fig. 3)

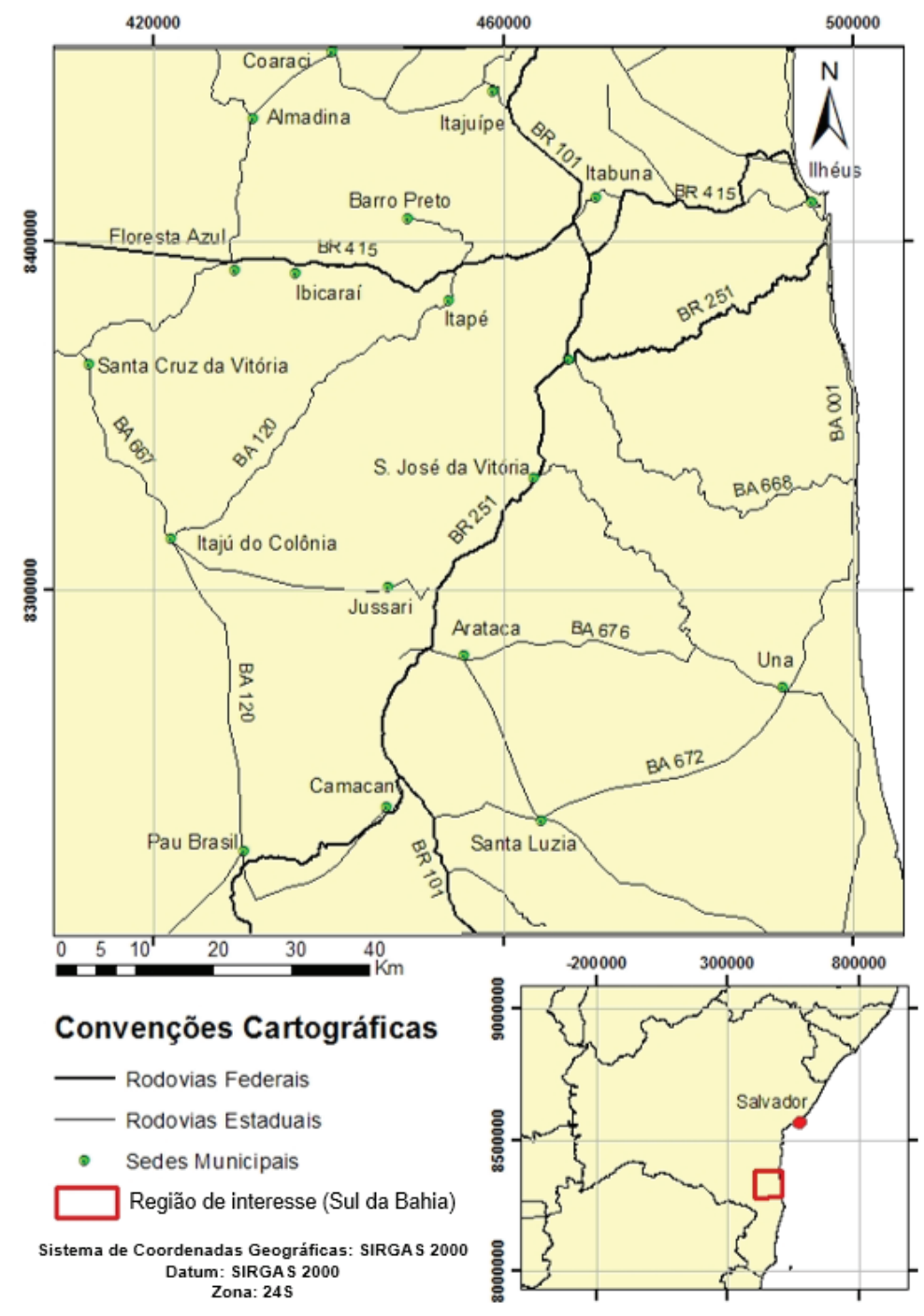

Figura 1. Mapa de localização da área de estudo dos diques de Ilhéus-Olivença. Figure 1. Location map of Ilhéus-Olivença dykes study area. 


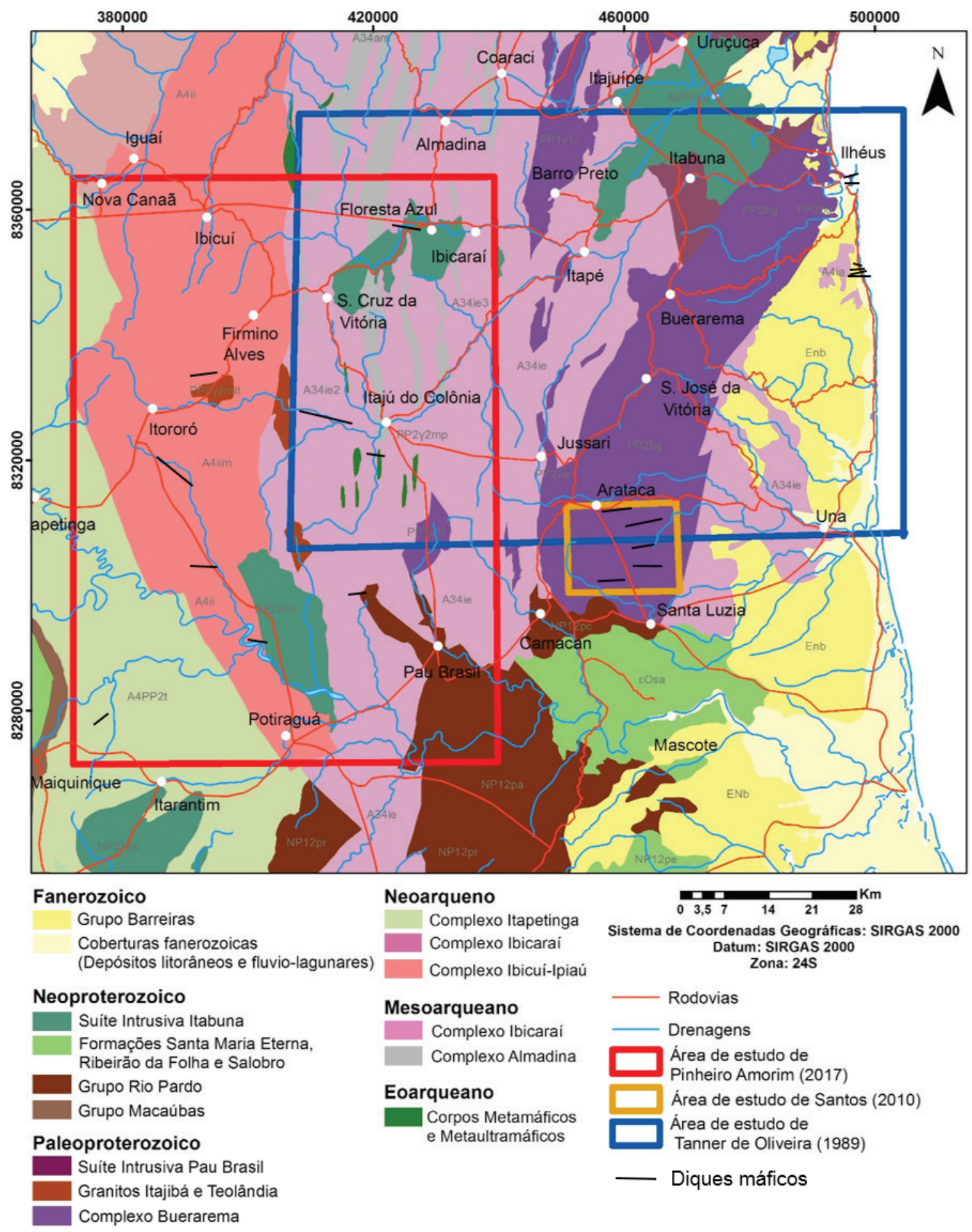

Figura 2. Mapa geológico do sul da Bahia. Fonte: CBPM/CPRM (2006).

Figure 2. Geological map of Southern Bahia. Source: CBPM/CPRM (2006). 


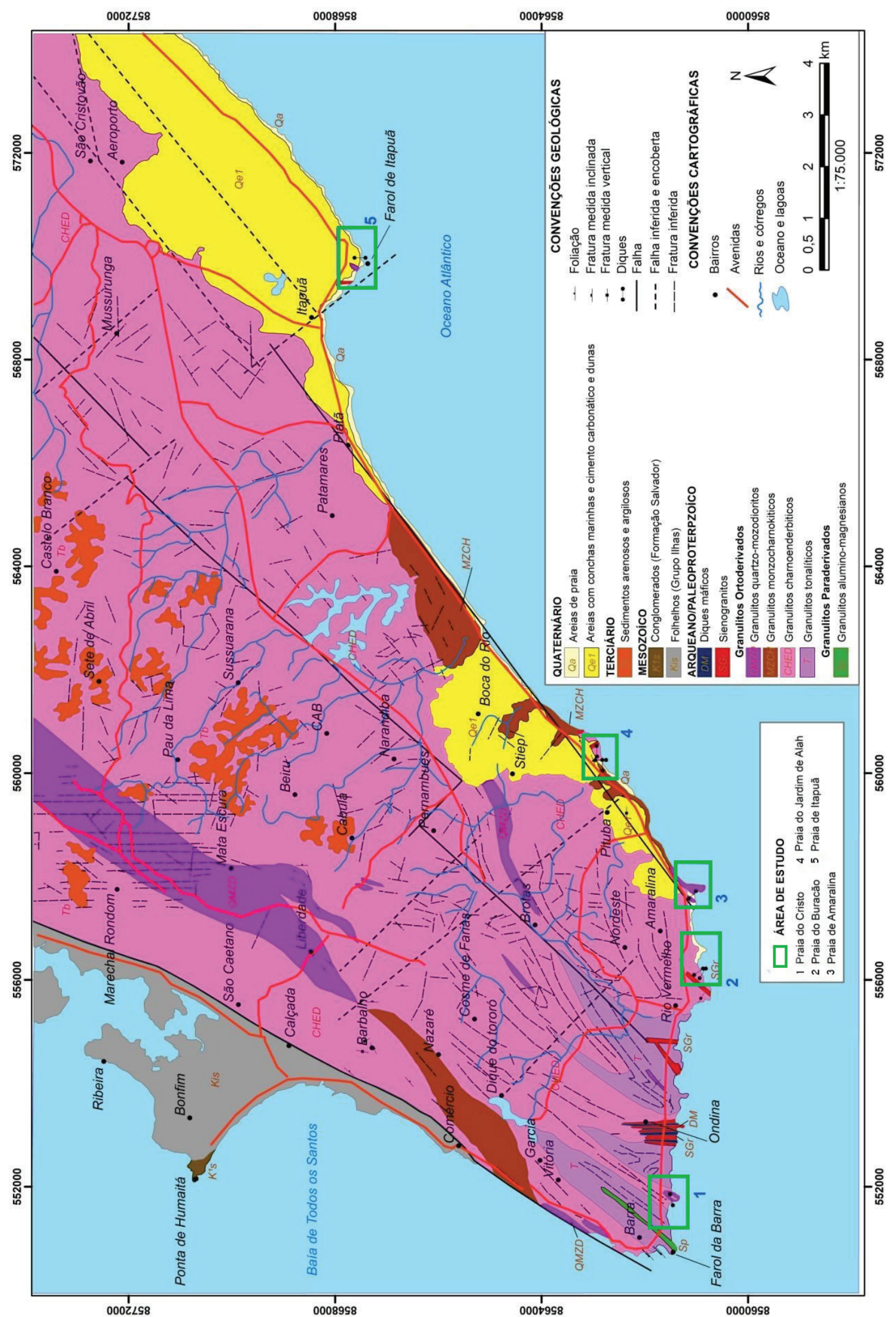

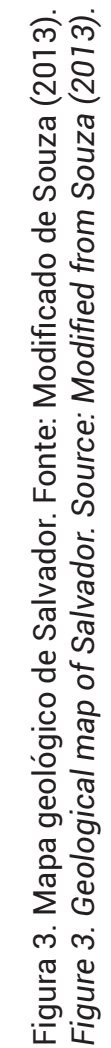




\subsection{Materiais e métodos}

A metodologia de trabalho envolveu três etapas: levantamento bibliográfico; coleta de dados petrográficos, geoquímicos e geocronológicos dos diques máficos da Província Litorânea; e integração, análise e comparação da coletânea desses dados.

Dez lâminas petrográficas dos diques máficos de Ilhéus-Olivença foram descritas utilizando o microscópio OLYMPUS-BX41 do LaboratóriodeMicroscopiaÓpticadaUniversidade Federal da Bahia. Para a litogeoquímica, as análises químicas de rocha total foram realizadas no SGS-Geosol Laboratório Ltda, utilizando a técnica de ICP-OES (Inductively Coupled Plasma - Optical Emission Spectrometry) para elementos maiores e ICP-MS (Inductively Coupled Plasma Mass Spectrometry) para os elementos traço. Os limites de detecção para a maioria dos elementos maiores ficaram na ordem de $0,01 \%$, enquanto os de elementos traço em 0,1 ppm. Além desses, foram compilados dados químicos de Tanner de Oliveira (1989) para o enxame de Ilhéus-Olivença.

Os dados petrográficos, geoquímicos e geocronológicos dos outros diques máficos da Província Litorânea para o estudo comparativo, foram retirados de Moraes Brito (1992), Cruz (2013) e Silva (2018) para Salvador, de Santos (2010) e Vieira (2016) para Camacan e de Pinheiro Amorim (2017) para Itajú do Colônia.

Os dados químicos foram tratados utilizando diagramas elaborados no software Geochemical Data Toolkit (GCDKit) versão 4.1 (Janousek, 2006) e planilhas da Microsoft Excel.

\section{Resultados}

\subsection{Diques Máficos de Ilhéus-Olivença}

\subsubsection{Aspectos de campo e petrográficos}

Os diques máficos de Ilhéus-Olivença apresentam cor cinza-escura a preta, granulação fina a média, isotrópicos, espessuras entre $20 \mathrm{~cm}$ e $30 \mathrm{~m}$, sendo dominante os menos espessos de até $3 \mathrm{~m}$. A forma desses corpos é predominantemente reta, porém também ocorrem sinuosos (Fig. 4A a F), mais raramente angulosos e, em alguns casos, apresentam bordas de resfriamento. Eles preenchem fraturas na encaixante granulítica pertencente aos complexos Buerarema e Ibicaraí, com trend E-W e direções variando de N80E a N100E.

No afloramento na praia da Concha foi observada estrutura de enclave rotacionado sugerindo fluxo magmático de leste para oeste (Fig. 4B), presença de assimilação da encaixante (Fig. 4C), xenólitos do embasamento granulítico em contato com os diques produzidos pela fragmentação das bordas durante o evento distensivo (Fig. 4D a F), bem como fraturas multidirecionais.

Petrograficamente, essas rochas apresentam granulação fina a média e assembleia mineral constituída essencialmente por plagioclásio, augita, olivina, hornblenda e opacos, sendo que a apatita e o zircão ocorrem como acessórios (Fig. 5A e B). As texturas identificadas foram intergranular, ofítica, porfirítica e, subordinadamente, subofítica. As amostras com textura porfirítica (Fig. 5C) apresentam fenocristais de plagioclásio, olivina e augita em uma matriz afanítica e no contato imediato dique/encaixante a matriz é criptocristalina. Processos de alteração secundária marcada pela sericitização, saussuritizaçãoo, uralizatização, biotitização e cloritização estão presentes (Fig. 5D).

\subsubsection{Aspectos geoquímicos}

A tabela 1 do material complementar mostra os dados químicos dos diques máficos de Ilhéus-Olivença. Nos diagramas a seguir são apresentados também as amostras dos diques máficos de Salvador, Camacan e Itajú do Colônia da PL, os quais serão discutidos no item 4.1.2 deste trabalho.

O diagrama A $\left(\mathrm{Na}_{2} \mathrm{O}+\mathrm{K}_{2} \mathrm{O}\right), \mathrm{F}$ (FeOt), M (MgO) (Irvine \& Baragar, 1971) para os diques de Ilhéus-Olivença (Fig. 6A) evidencia a afinidade toleítica dessas rochas, com o trend de enriquecimento em $\mathrm{FeO}_{\mathrm{t}}$ em relação ao $\mathrm{MgO}$. Essas rochas filonianas foram classificadas como basaltos no diagrama da figura 6B (Le Bas et al., 1986), majoritariamente com afinidade subalcalina/toleítica, em ambiente intraplaca 

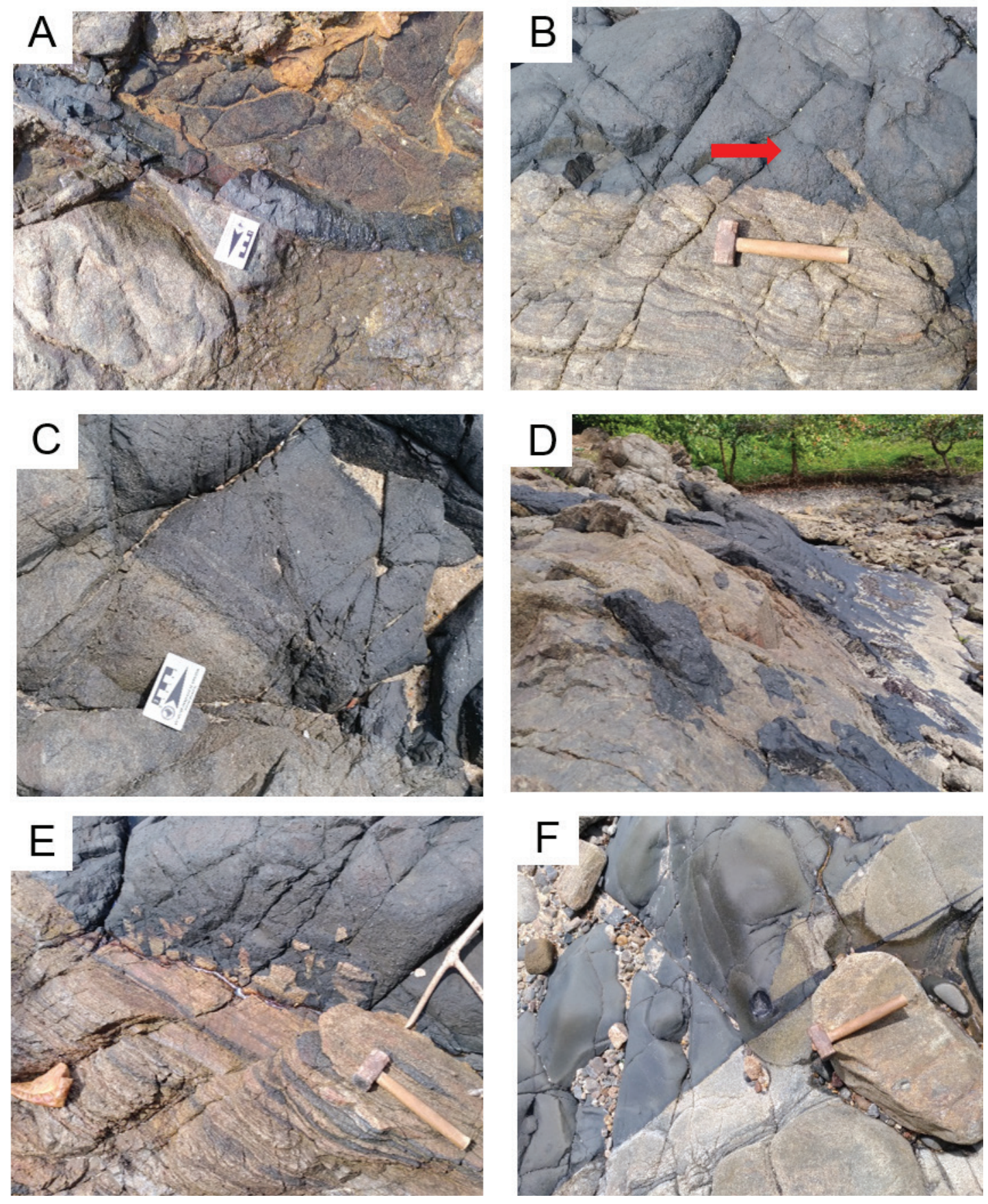

Figura. 4. Aspectos de campo dos diques máficos de Ilhéus-Olivença. A) Dique com $10 \mathrm{~cm}$ de espessura e forma sinuosa na praia de Olivença. Coordenadas: 8348387,97 m S/498634,32 m E; B) Estrutura de enclave rotacionado, indicando direção do fluxo magmático de leste para oeste representada pela seta vermelha, na praia da Concha. Coordenadas: $8363052,14 \mathrm{~m} \mathrm{~S} / 497433,99 \mathrm{~m} \mathrm{E}$; C) Feição de assimilação da encaixante no contato de dique da praia da Concha. Coordenadas: 8363064,68 m S/497449,99 m E.; D) Contato sinuoso de dique e xenólitos na encaixante na praia da Concha. Coordenadas: 8363122,58 m S/497435,20 m E; E) Enclaves de rocha granulítica em contato de dique máfico na praia da Concha. Coordenadas: 8363133,07 m S/497412,94 m E; F) Feição de englobamento de enclave em dique da praia de Olivença. Coordenadas: 8348302,64 m S/498845,74 m E

Figure 4. Field aspects of Ilhéus-Olivença mafic dykes. A) Dyke $10 \mathrm{~cm}$ thick and sinous form on Olivença beach. Coordinates: $8348387,97 \mathrm{~m} \mathrm{~S} / 498634,32 \mathrm{~m} \mathrm{E}$; B) Enclave rotated structure, indicating direction of the magmatic flow from east to west represented by the red arrow, at Concha beach. Coordinates: 8363052,14 m S/497433,99 m E; C) Feature of assimilation of the embedding rock in the contact of dike of Concha beach. Coordinates: 8363064,68 m S/497449,99 $m \mathrm{E} ; \mathrm{D})$ Sinuous contact of dyke and xenoliths in the embedding rock. Coordinates: $8363122,58 \mathrm{~m} \mathrm{S/497435,20} \mathrm{m} \mathrm{E;} \mathrm{(E)}$ Enclaves of granulitic rock in contact with mafic dyke at Concha beach. Coordinates: 8363133,07 m S/497412,94 m E; F) Feature of embedding enclave in dike of Olivença beach. Coordinates: 8348302,64 m S/498845,74 m E. 

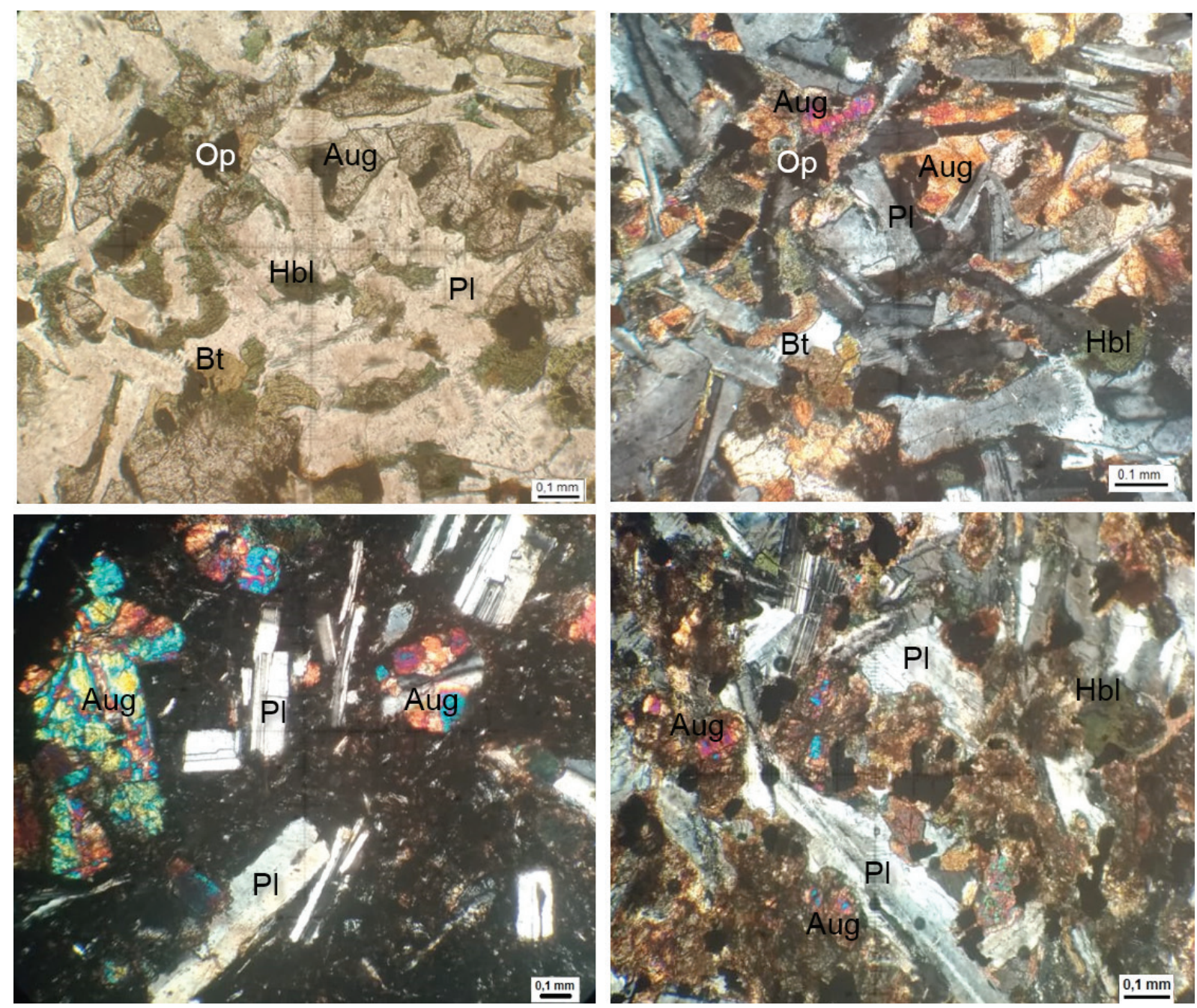

Figura 5. Fotomicrografias dos diques máficos de Ilhéus-Olivença. A) Aspecto geral da textura subofítica e intergranular, com plagioclásio $(\mathrm{Pl})$, piroxênio $(\mathrm{Px})$, hornblenda $(\mathrm{Hbl})$ e biotita $(\mathrm{Bt})$ presentes, aumento de $100 \mathrm{X}$, sem analisador; $\mathrm{B})$ com analisador; C) Detalhe da textura porfirítica com fenocristais de plagioclásio (PI) e augita (Aug), aumento de 100X, com analisador; D) Detalhe da textura subofítica, aumento de 100X, com analisador.

Figure 5. Photomicrographies of the Ilhéus-Olivença mafic dykes. A) General aspect of the subofitic and intergranular textures, with plagioclase $(\mathrm{Pl})$, pyroxenes $(\mathrm{Px})$, hornblende $(\mathrm{Hbl})$ and biotite $(\mathrm{Bt}), 100 \mathrm{X}$ magnification, without analyzer; $\mathrm{B})$ with analyzer; $C$ ) Detail of the porphyritic texture with plagioclase (PI) and augite (Aug) phenocrystals, 100X magnification, with analyzer; D) Subofitic texture detail, 100X magnification, with analyzer.

(Fig. 7). No entanto, observa-se um conjunto de amostras com teores menores de $\mathrm{Zr}$ que plotaram na interface com basaltos de arco de ilha.

Os diques são constituídos por rochas básicas com teores de $\mathrm{MgO}$ que variam entre 4,06 e 9,08\%, enquanto o $\mathrm{SiO}_{2}$ possui teores de 43,49 a 49,95\%. O teor de mg\# [MgO/ (MgO+FeOt)] varia entre 0,21 e 0,44, evidenciando que esses diques foram originados de magmas basálticos evoluídos, uma vez que os valores para magmas primitivos variam entre 0,74 e 0,80 (Takahashi \& Kushiro, 1983). Diagramas de variação dos elementos maiores evidenciam que os diques máficos de Ilhéus-Olivença (Fig. 8) apresentaram enriquecimento em $\mathrm{SiO}_{2}, \mathrm{TiO}_{2}, \mathrm{NaO}_{2}, \mathrm{~K}_{2} \mathrm{O}, \mathrm{P}_{2} \mathrm{O}_{5}$ e FeOt durante a evolução magmática. $\mathrm{Al}_{2} \mathrm{O}_{3}$ e $\mathrm{CaO}$ diminuem seus teores com o avanço da cristalização, o que reflete a importância do plagioclásio e do clinopiroxênio nesse processo.

Os diagramas de variação dos elementos traço (Fig. 9) evidenciam que os HFSE (High Field Strength Elements) representados por $\mathrm{Nb}$, Y, Zr e La e LILE (Large Ion Litophile Elements) representados por $\mathrm{Ba}, \mathrm{Rb}$ e $\mathrm{Sr}$ apresentaram comportamento semelhante, todos aumentam seus teores com a evolução magmática. O Ni apresenta diminuição de teor durante a cristalização, demonstrando seu caráter compatível. 

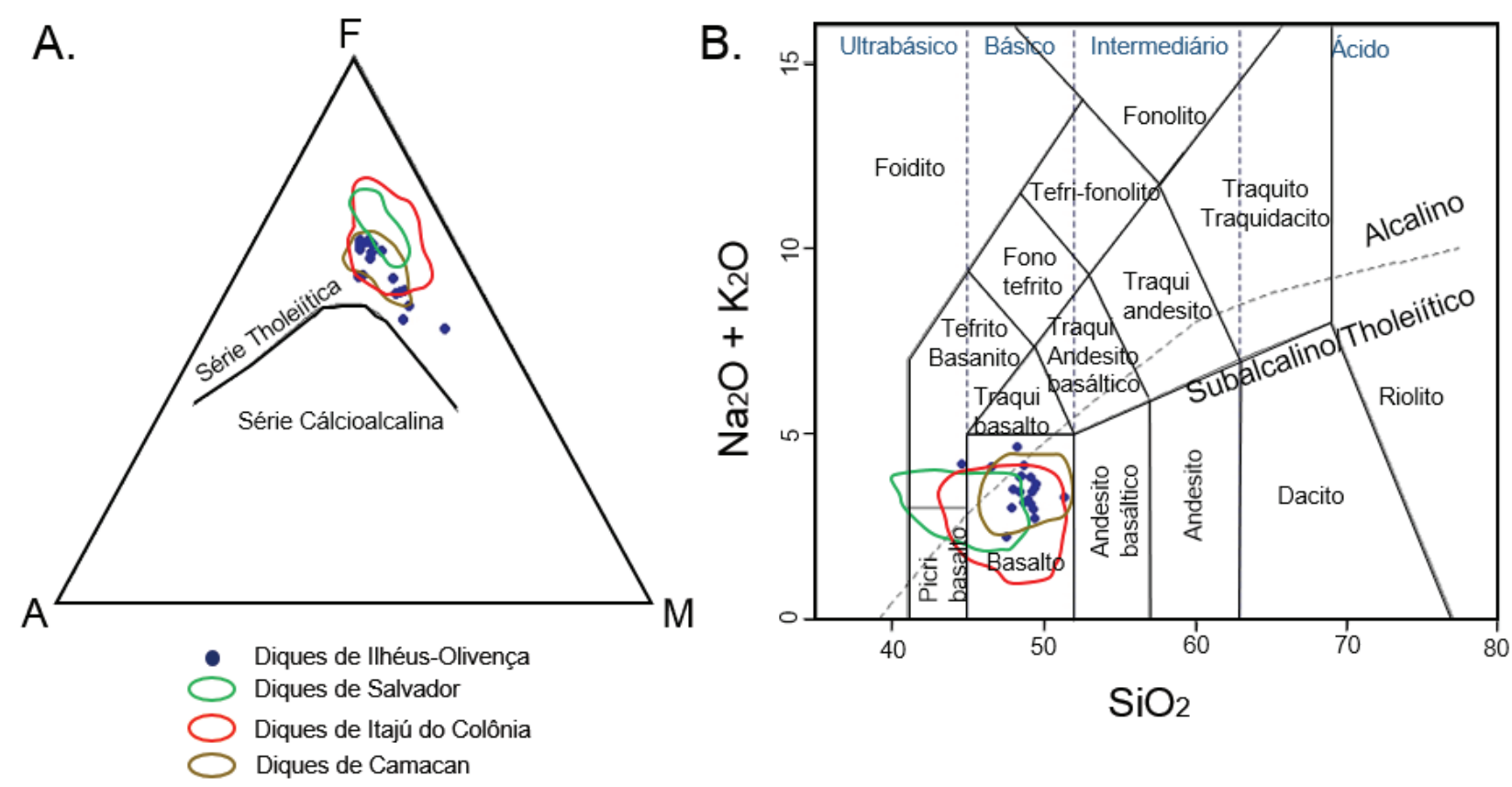

Figura 6. Diagramas de Classificação. A) Diagrama A ( $\left.\mathrm{Na}_{2} \mathrm{O}+\mathrm{K}_{2} \mathrm{O}\right), \mathrm{F}\left(\mathrm{FeO}_{\mathrm{t}}\right), \mathrm{M}(\mathrm{MgO})$, segundo Irvine \& Baragar (1971); $\left.\mathrm{B}\right)$ Diagrama $\mathrm{Na}_{2} \mathrm{O}+\mathrm{K}_{2} \mathrm{O}$ versus $\mathrm{SiO}_{2}$ (Le Bas et al., 1986), para os diques máficos da Província Litorânea.

Figure 6. Classification Diagrams. A) A $\left(\mathrm{Na}_{2} \mathrm{O}+\mathrm{K}_{2} \mathrm{O}\right), \mathrm{F}(\mathrm{FeO}), \mathrm{M}(\mathrm{MgO})$ diagram, according Irvine \& Baragar (1971); B) $\mathrm{Na}_{2} \mathrm{O}+\mathrm{K}_{2} \mathrm{O}$ versus $\mathrm{SiO}_{2}$ diagram (Le Bas et al., 1986), for the Coastal Province mafic dykes.

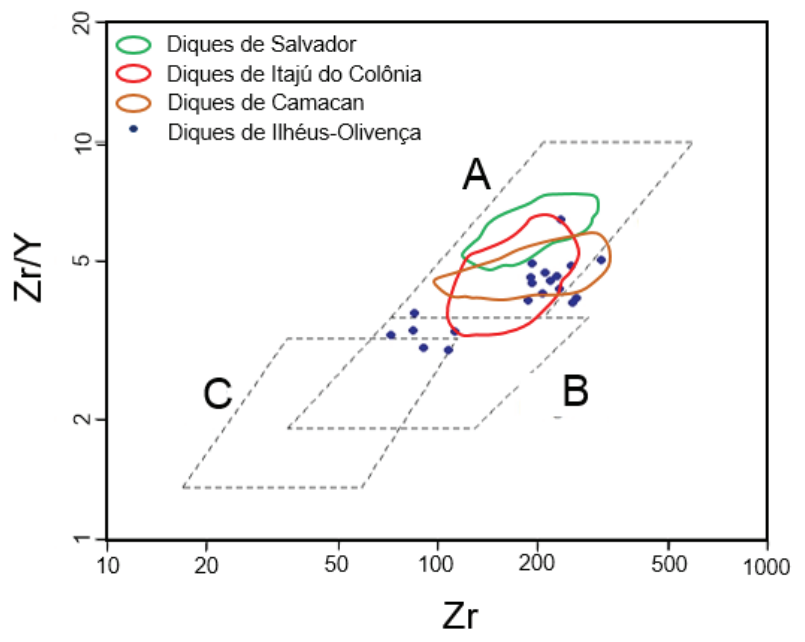

Figura 7. Diagrama discriminante log. Zr versus log. Zr/Y (Pearce \& Norry, 1979) para os diques máficos da Província Litorânea. A- Basaltos Intraplaca, B- Basaltos de Arco de Ilha, C- Basaltos de Cordilheira Mesoceânica.

Figure 7. Discrimination diagram log. $\mathrm{Zr}$ versus log. $\mathrm{Zr} / \mathrm{Y}$ (Pearce \& Norry, 1979) for the Ilhéus-Olivença and Coastal Province mafic dykes. A- Intraplate Basalts, B- Island. Arc Basalts, C-Mesoceanic Ridge Basalts.
O padrão de distribuição dos ETR (Fig. 10A) normalizados para omanto primitivo(McDonough \& Sun, 1995) indicam pouco fracionamento, com disposição quase sub-horizontal e levemente enriquecidas em ETRL (leves) em relação ao ETRP (pesados). Comparando os padrões dos diques de Ilhéus-Olivença com reservatórios do N-MORB (Normal Mid-Ocean Ridge Basalt), E-MORB (Enriched Mid-Ocean Ridge Basalt) e OIB (Ocean Island Basalt), verifica-se que esses diques apresentam padrões entre E-MORB e OIB (Fig. 10B). A figura 11A apresenta o padrão de elementos incompatíveis, normalizado para o manto primitivo (McDonough \& Sun, 1995), para os diques de Ilhéus-Olivença, no qual são observadas anomalias positivas em $\mathrm{Ba}$ e $\mathrm{Ti}$ e negativas em $\mathrm{Nb}$ e Sr. A anomalia em Ba pode ser causada por adição de sedimentos na fonte (Sun \& McDonough, 1989), enquanto que a de Sr pode estar relacionada ao fracionamento de plagioclásio. Comparado aos padrões N-MORB, E-MORB, OIB e GLOSS (Global Subducting Sediments - Plank \& Langmuir, 1998) da figura 11B é observado que as rochas em estudo são semelhantes aos E-MORB e OIB. 

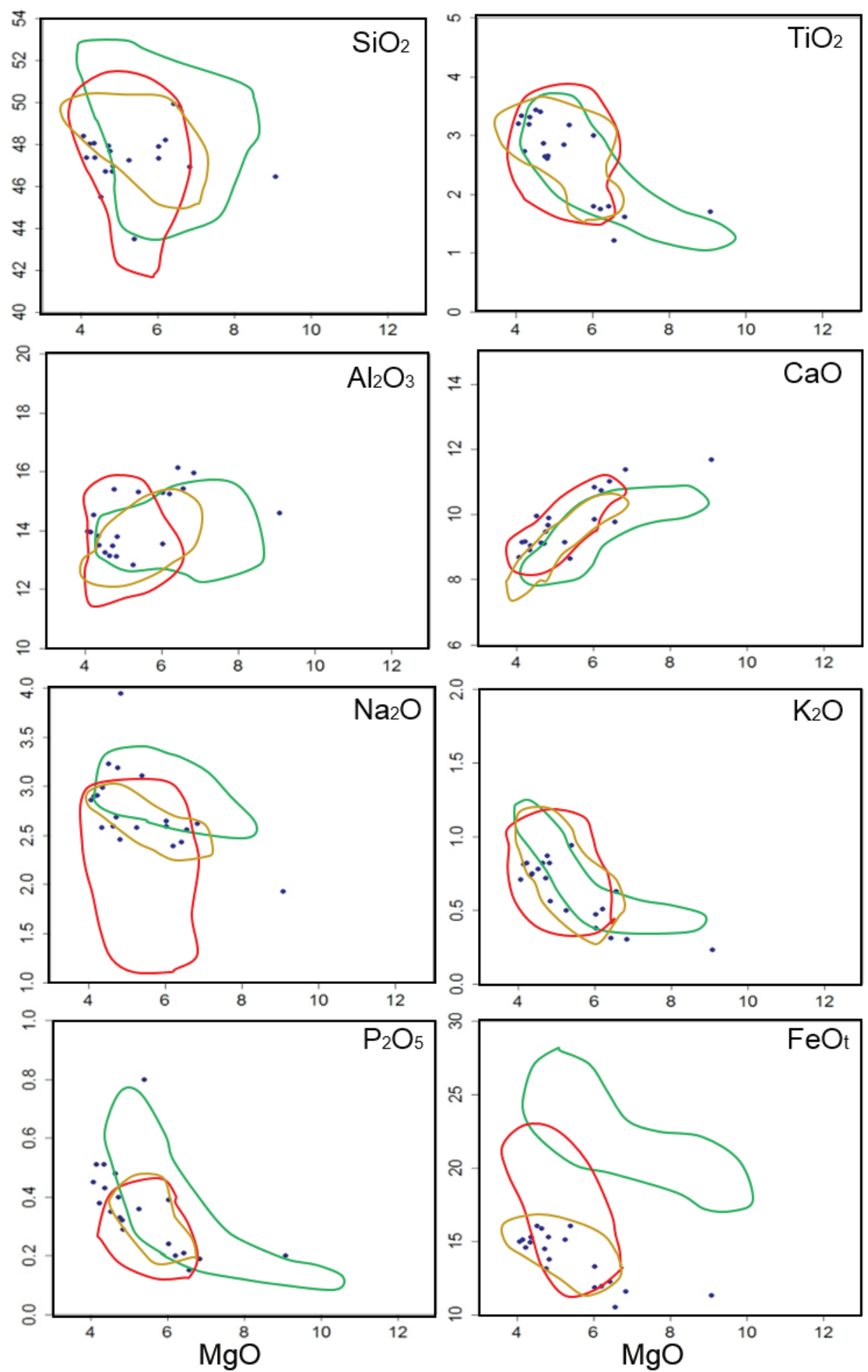

Diques de Salvador

Diques de Camacan

Diques de Itajú do Colônia

- Diques de Ilhéus-Olivença

Figura 8. Diagramas de variação entre MgO (\% em peso) versus elementos maiores (\% em peso) para os diques máficos da Província Litorânea.

Figure 8. Variation diagrams $\mathrm{MgO}$ (wt\%) versus major elements (wt\%) for the Coastal Province mafic dykes. 

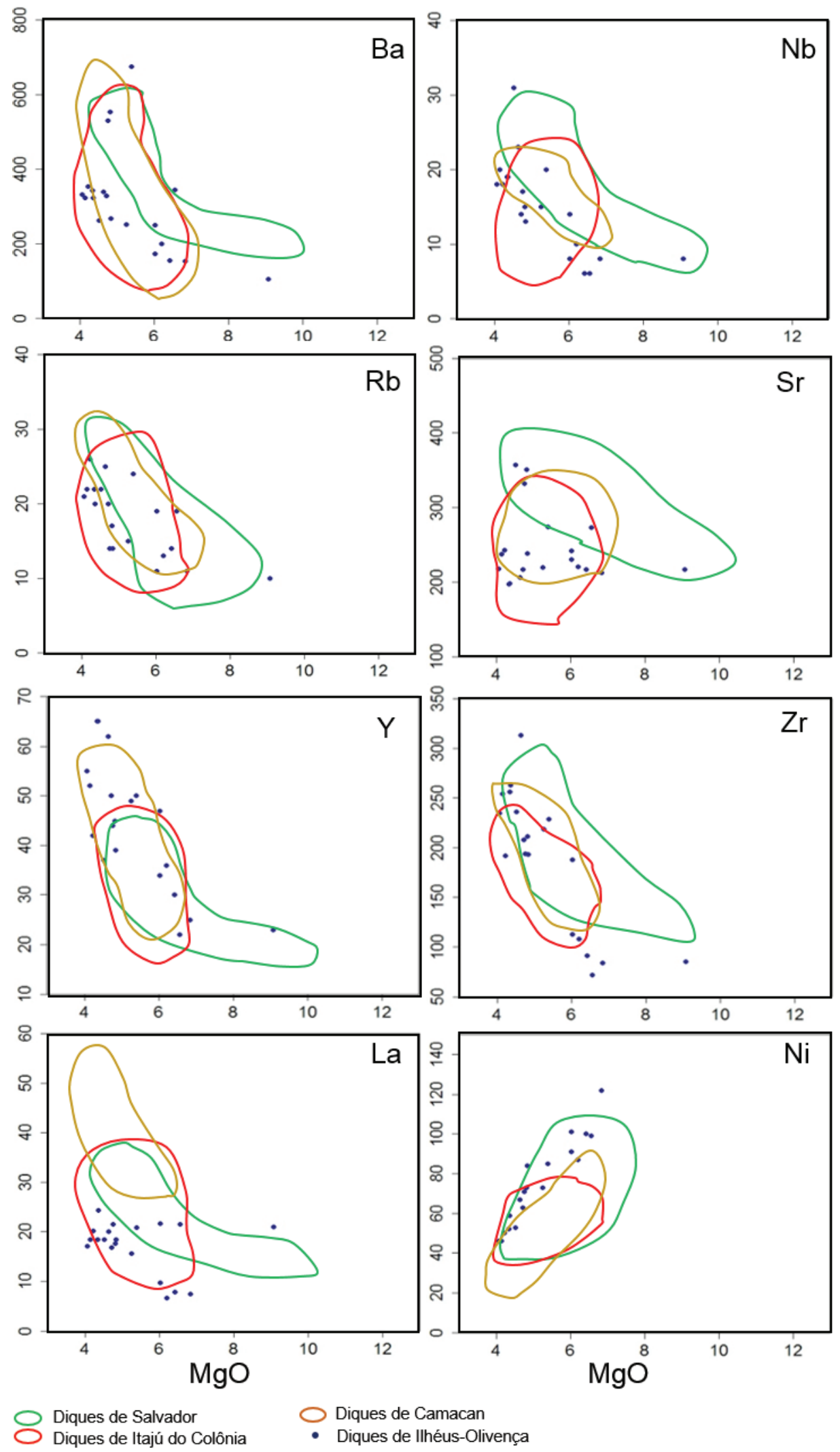

Figura 9. Diagramas de variação entre $\mathrm{MgO}$ (\% em peso) versus elementos traço (ppm) para os diques máficos da Província Litorânea.

Figure 9. Variation diagrams $\mathrm{MgO}$ (wt\%) versus trace elements (ppm) for the Coastal Province mafic dykes. 

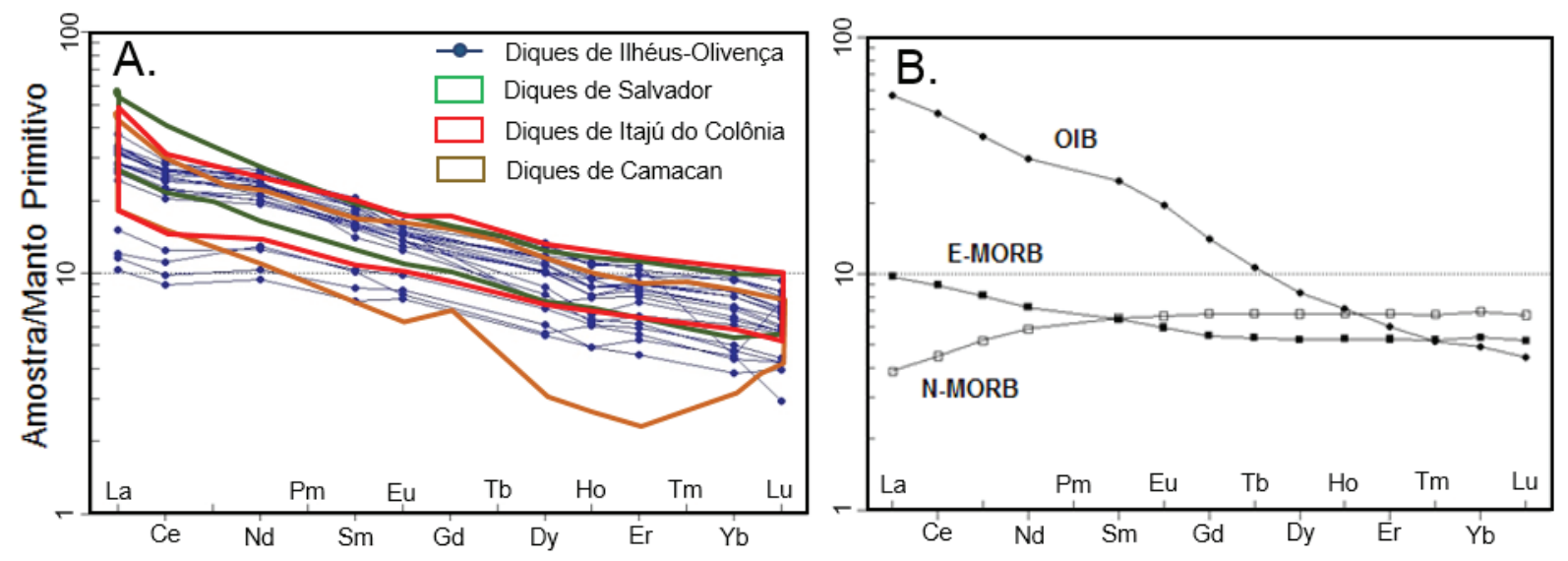

Figura 10. Padrão de distribuição dos ETR normalizados pelo manto primitivo, segundo McDonough \& Sun (1995). A) Diques máficos da Província Litorânea; B) Reservatórios OIB (Ocean Island Basalt), E-MORB (Enriched Mid-Ocean Ridge Basalt) e N-MORB (Normal Mid-Ocean Ridge Basalt, de acordo com Sun \& McDonough (1989).

Figure 10. Rare-earth elements patterns normalized to primtive mantle according McDonough \& Sun (1995). A) Coastal Province mafic dykes; B) OIB (Ocean Island Basalt), E-MORB (Enriched Mid-Ocean Ridge Basalt) and N-MORB (Normal Mid-Ocean Ridge Basalt reservoirs, according Sun \& McDonough (1989).
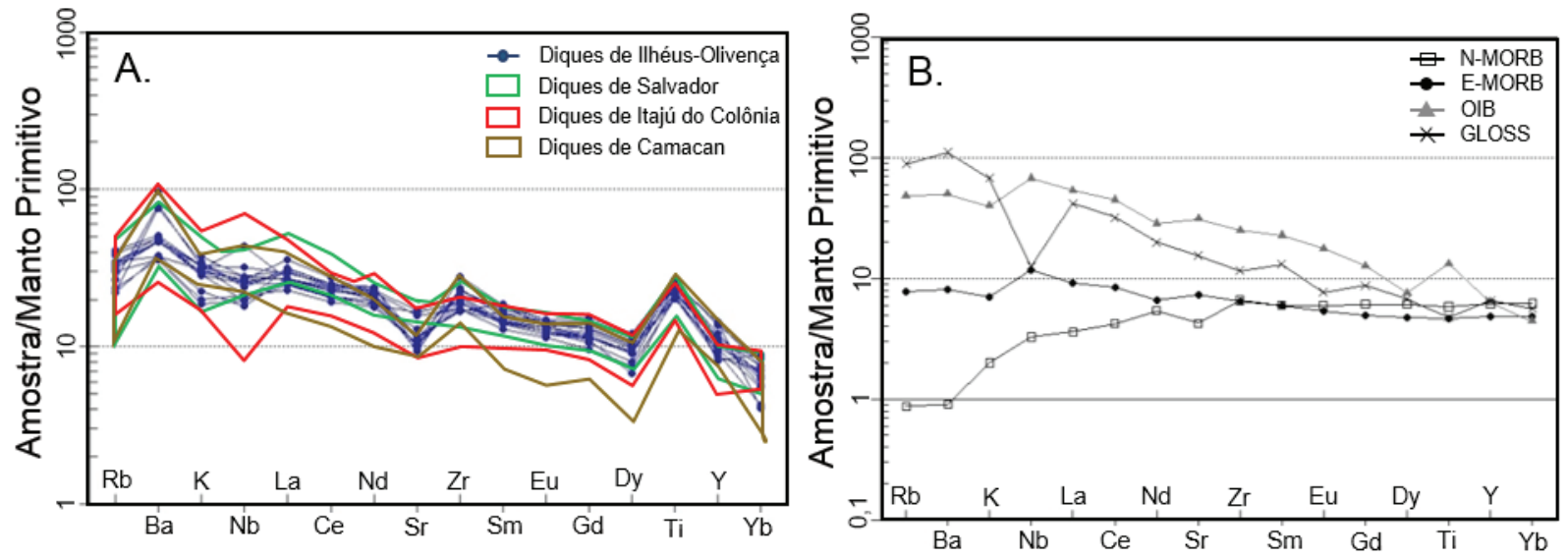

Figura 11. Diagramas multielementares normalizados pelo manto primitivo, segundo Sun \& McDonough (1989). A) Diques máficos da Província Litorânea; B) Reservatórios N-MORB, E-MORB, OIB (Sun \& McDonough, 1989) e GLOSS (Plank \& Langmuir, 1998).

Figure 11. Spidergram normalized to primitive mantle according Sun \& McDonough (1989). A) Coastal Province mafic dykes; B) N-MORB, E-MORB, OIB (Sun \& McDonough, 1989) reservoirs and GLOSS (Plank \& Langmuit, 1998).

\section{Discussões dos resultados}

4.1 Estudo comparativo dos diques máficos da Província Litorânea (Diques máficos de Salvador, Camacan e Itajú do Colônia)

\subsubsection{Aspectos de campo e petrográficos}

Os diques máficos de Camacan e Itajú do Colônia são intrusivos em rochas granulíticas pertencente aos complexos Buerarema e Ibicaraí, enquanto que os de Salvador intrudem granulitos do Cinturão Salvador-Esplanada-Boquim. Eles apresentam, de forma geral, granulação fina a média, isotrópicos, com espessuras de poucos centímetros a dezenas de metros, sendo os mais espessos identificados em Salvador, que podem chegar até $50 \mathrm{~m}$ (Fig. 12A). Os contatos com as encaixantes granulíticas são predominantemente retos e sinuosos (Fig. 12A a C). 
Os corpos filonianos que ocorrem no sul do estado (Camacan e Itajú do Colônia) estão encaixados em fraturas distensionais com orientação preferencial aproximadamente E-W, também ocorrendo NW-SE e NE-SW, enquanto os de Salvador predomina a direção NNW-SSE, embora tenham diques E-W. Em Salvador são observadas estruturas indicando direção do fluxo magmático de sul para norte (Fig. 12B), enquanto que em Camacan o fluxo foi de oeste para leste (Fig. 12D). No caso de Itajú do Colônia, os diques estão truncados por corpos félsicos (Fig. 12E) e apresentam fraturas multidirecionais (Fig. 12F).

Os diques máficos mostram grandes similaridades mineralógicas e texturais, apresentando assembleia mineralógica essencial constituída por plagioclásio, piroxênios e, por vezes, hornblenda (Fig. 13A a F). A olivina ocorre somente nos diques de Salvador (Fig. 13A e B). As texturas são ofítica, subofítica, intergranular e, em alguns casos, porfirítica (Fig. 13E) com fenocristais de plagioclásio e piroxênios imersos em uma matriz afanítica. Essas rochas apresentam processos de uralitização (Figura 13F), sericitização, saussuritização, biotitização e cloritização.

\subsubsection{Aspectos geoquímicos}

Nas tabelas 2, 3 e 4 do material suplementar encontram-se as análises químicas dos diques máficos de Salvador (Silva, 2018), Camacan (Santos, 2010) e Itajú do Colônia (Pinheiro Amorim, 2017), respectivamente.

Todos os diques da PL quando plotados no diagrama AFM mostram trend de enriquecimento em ferro em relação ao MgO (Fig. 6A), sendo classificados como toleíticos. No diagrama da figura $6 \mathrm{~B}$ essas rochas foram classificadas predominantemente como basaltos e com afinidade subalcalina/toleítica e natureza intraplaca (Fig. 7).

O comportamento dos elementos maiores (Fig. 8) mostrou um fracionamento caracterizado pelo aumento dos óxidos $\mathrm{SiO}_{2}, \mathrm{TiO}_{2^{\prime}}, \mathrm{FeO}_{\mathrm{t}^{\prime}} \mathrm{K}_{2} \mathrm{O}$, $\mathrm{Na}_{2} \mathrm{O}$ e $\mathrm{P}_{2} \mathrm{O}_{5}$ com a evolução magmática, e pela diminuição do $\mathrm{Al}_{2} \mathrm{O}_{3}$ e do $\mathrm{CaO}$, evidenciando a participação do plagioclásio e do clinopiroxênio na cristalização fracionada. O teor de mg\# dos conjuntos de diques da PL (Salvador mg\# 0,15-
0,55; Camacan mg\# 0,19-0,33 Itajú do Colônia mg\# 0,15-0,34) estão muito próximos indicando que foram formados a partir de magmas basálticos evoluídos que experimentaram diferenciação durante a colocação. Quanto ao comportamento dos elementos traço da $\mathrm{PL}$ (Fig. 9), tanto os elementos HFS quanto os LIL, apresentaram aumento em seu teor com a diminuição do $\mathrm{MgO}$, exceto o Ni que mostra correlação positiva com o MgO.

O padrão de ETR normalizado para o manto primitivo (Fig. 10A) mostrou para todos os conjuntos da PL um enriquecimento em ETRL em relação aos pesados e paralelismo entre os padrões, evidenciando que possivelmente esses diques foram formados a partir de uma mesma fonte mantélica. Comparando os padrões da PL com o do N-MORB (Normal Mid-Ocean Ridge Basalt), E-MORB (Enriched Mid-Ocean Ridge Basalt) e OIB (Ocean Island Basalt), verifica-se que esses diques apresentam valores de padrões entre E-MORB e OIB (Fig. 10B). Os diques máficos daPL não exibem anomalias de Eu ea razão média de Eu/Eu* encontrada foi 0,95, evidenciando que a evolução desse magmatismo dependeu pouco do fracionamento do plagioclásio. Os padrões de elementos incompatíveis (Fig. 11A) normalizado pelo manto primitivo (McDounogh \& Sun, 1995) são semelhantes com anomalias positivas em Ba e Ti bem marcadas e negativas em Sr. Anomalias negativas discretas de $\mathrm{Nb}$ também estão presentes em algumas amostras. Comparando os padrões da PL com os de N-MORB, E-MORB, OIB e GLOSS (Fig. 11B) é observado que eles são compatíveis com E-MORB e OIB.

\subsubsection{Natureza da fonte mantélica}

As correlações entre $\mathrm{Zr}$ e elementos incompatíveis (EI) são excelentes indicadores petrogenéticos devido à pouca mobilidade durante a evolução magmática, preservando as características das fontes mantélicas que originaram as rochas basálticas (e.g. Weaver, 1991). Os diagramas da figura 14 apresentam correlações positivas entre Zr e La, Y, Nd e Ce para os diques máficos da PL com maiores variações para as amostras de Camacan, indicando pouca heterogeneidade da fonte mantélica. 

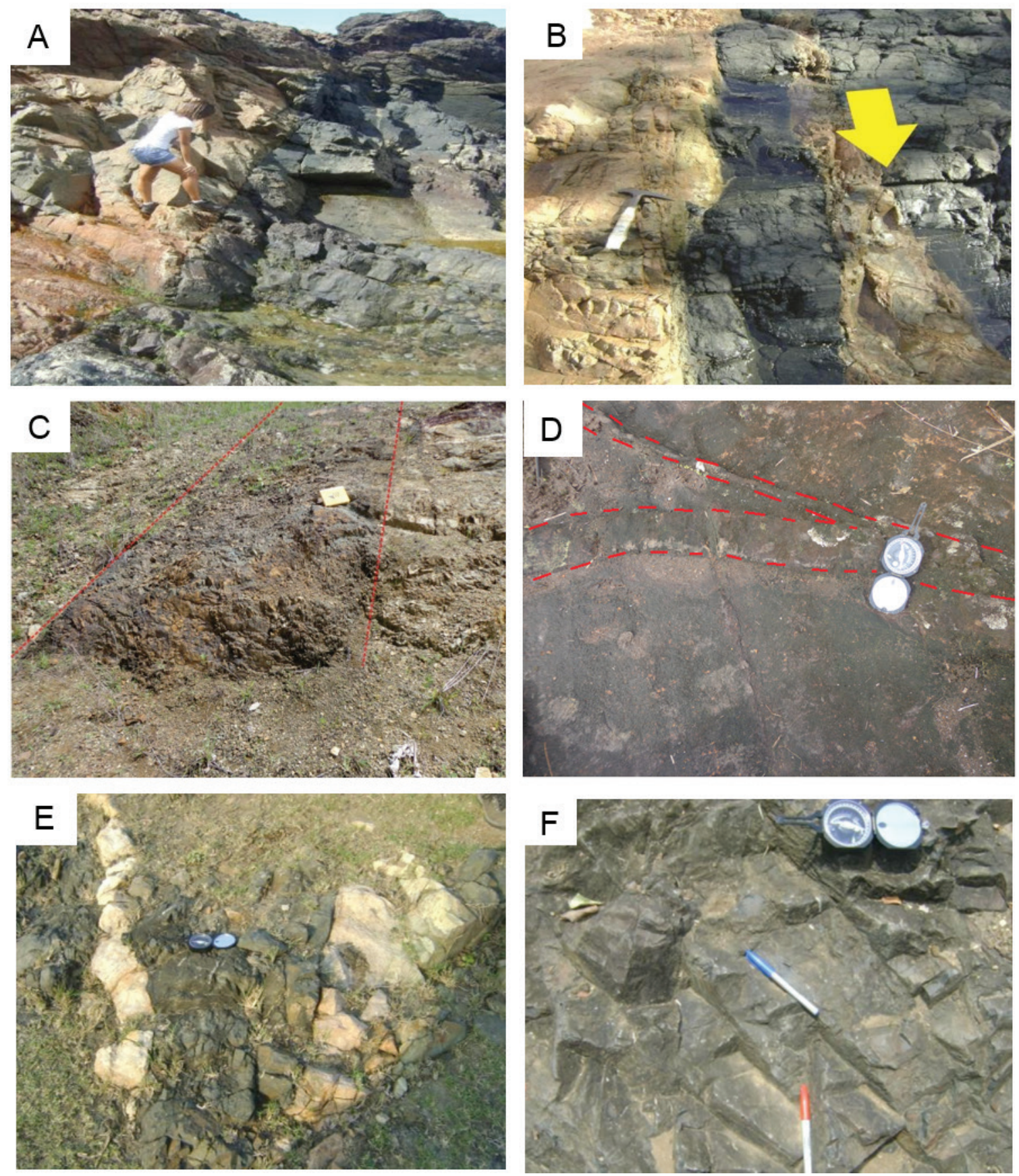

Figura 12. Fotografias de campo dos diques máficos. Diques máficos de Salvador (Cruz, 2013): A) Dique com $50 \mathrm{~m}$ de espessura na praia de Ondina; B) Estrutura de englobamento indicando direção do fluxo magmático de sul para norte (seta amarela), e a ponta do martelo indica o norte. Diques máficos de Camacan (Santos, 2010): C) Dique com granulação média e espessura de $1 \mathrm{~m}$ em contato com a encaixante granulítica; D) Dique com granulação fina, 11 $\mathrm{cm}$ de espessura e estrutura em vermelho indicando direção do fluxo magmático de leste para oeste. Diques máficos de Itajú do Colônia (Pinheiro Amorim, 2017): E) Diques félsicos truncando o dique máfico; F) Dique máfico mostrando faturamento multidirecional $\mathrm{N}^{\circ} 70^{\circ}$ e $\mathrm{N} 50^{\circ}$, marcados pelas canetas azul e vermelha respectivamente.

Figure 12. Field photographs of the mafic dykes. Salvador mafic dykes (Cruz, 2013): A) $50 \mathrm{~m}$ thick dyke on Ondina beach; B) Embedding structure indicating the direction of the magmatic flow from south to north (yellow arrow), and the tip of the hammer indicates the north. Camacan mafic dykes (Santos, 2010): C) Dike with medium size and thickness of $1 \mathrm{~m}$ in contact with the granulite rocks; D) Dike with fine granulometry, $11 \mathrm{~cm}$ thick and structure in red indicating direction of the magmatic flow from east to west. Itajú do Colônia mafic dykes (Pinheiro Amorim, 2017): E) Felsic dykes truncating the mafic dyke; F) Mafic dike showing multidirectional fractures $\mathrm{N}^{\circ} 70^{\circ}$ and $\mathrm{N} 150^{\circ}$, marked by the blue and red pens respectively. 

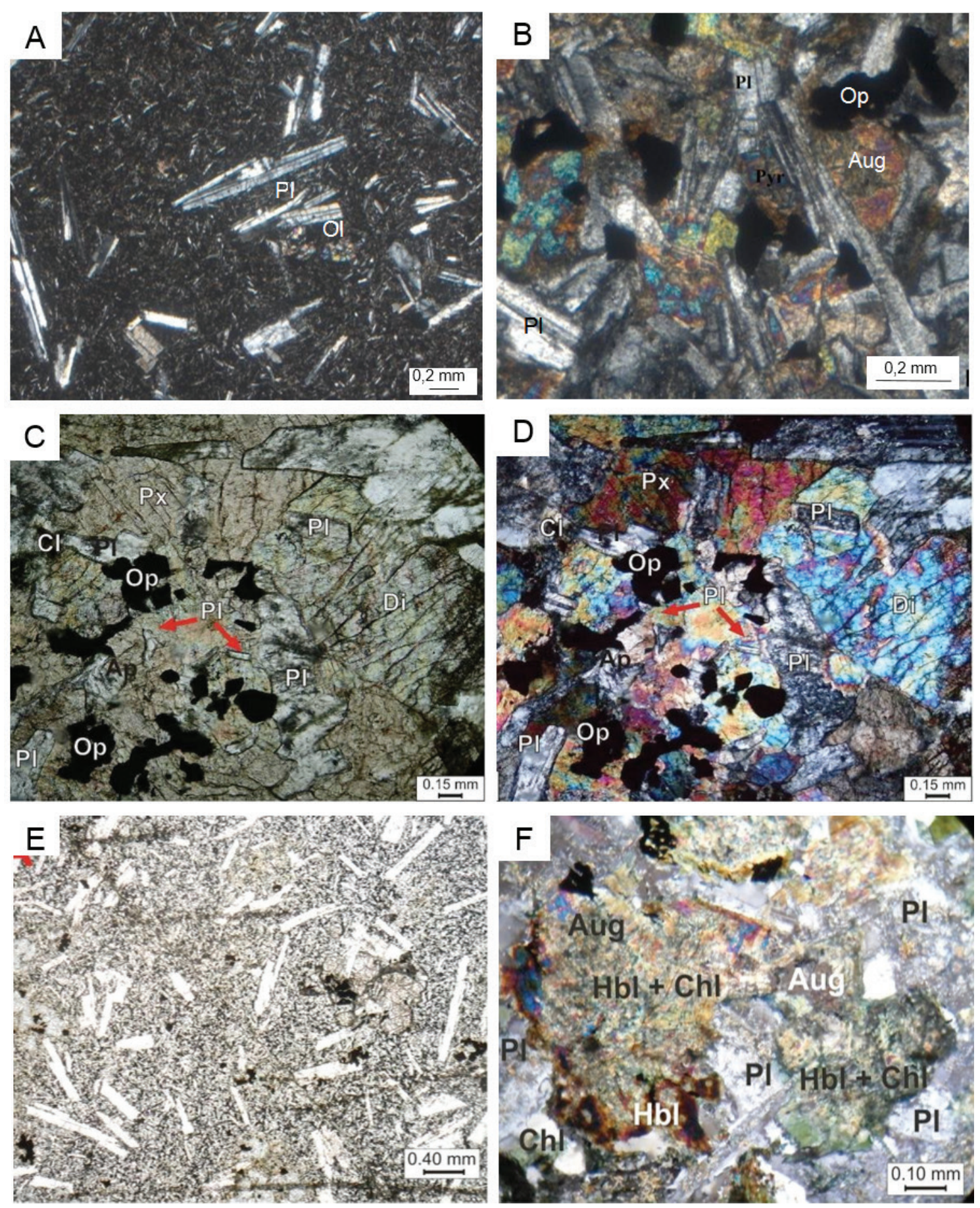

Figura 13. Fotomicrografias dos diques máficos. Diques máficos de Salvador (Cruz, 2013): A) Cristais de olivina (Ol) e plagioclásio $(\mathrm{Pl})$ circundados por matriz afanítica, em amostra da praia de Jardim de Alah, polarizadores cruzados. Aumento de 25X; B) Textura subofítica em amostra da praia de Itapuã, polarizadores cruzados. Aumento de 100X. Diques máficos de Camacan (Santos, 2010): C) Aspecto geral das texturas ofítica e subofítica, luz plana. Aumento de 100X; D) polarizadores cruzados. Diques máficos de Itajú do Colônia (Pinheiro Amorim, 2017): E) Texturas porfirítica e glomeroporfirítica, com micro e fenocristais de plagioclásio (PI) e piroxênio (Py) imersos em matriz fina, com analizador. Aumento de 25X; F) Aspecto geral de amostra de dique máfico de Itajú do Colônia, com cristais de augita uralitizados, polarizadores cruzados. Aumento de 200X. Di - diopsídio; Aug - augita; Op - minerais opacos; Ap - apatita; Bt - biotita; Chl - clorita.

Figure 13. Photomicrographs of the mafic dykes. Salvador mafic dykes (Cruz, 2013) A) Olivine and plagioclase crystals surrounded by aphanitic matrix in a sample of Jardim de Alah beach, crossed polarizers. 25X increase. B) Subofitic texture in a sample of Itapuã beach, crossed polarizers. 100X magnification. Camacan mafic dykes (Santos, 2010) C) General aspect of the ofitic and subofitic textures, 100X magnification, flat light and D) crossed polarizers. Itajú do Colônia mafic dykes (Pinheiro Amorim, 2017) E) Porphyritic and glomeroporphyritic textures, with micro- phenocrystals of plagioclase and pyroxene immersed in a fine matrix, 25X magnification with analyzer. F) General aspect of the mafic dike sample from Itajú do Colônia, with uralized augite crystals, crossed polarizers. 200X magnification. Plagioclase; Pyropyroxene; Di- diopside; Aug - augite; Ol - Olivine; Op - opaque minerals; Ap - apatite; $\mathrm{Bt}$ - biotite; $\mathrm{Cl}$ - chlorite; Rbk - riebeckite. 
As razões de ETRs apresentadas na tabela 1 são similares paras os quatro conjuntos de diques da PL, confirmando o comportamento típico de magmatismo toleítico, com enriquecimento em ETRL [média $(\mathrm{La} / \mathrm{Sm}) \mathrm{n}=2,27 \pm 0,45$ ] e empobrecimento de ETRP [média (Sm/Yb) $\mathrm{n}=2,30 \pm 0,21]$. Os valores da razão $(\mathrm{La} / \mathrm{Yb}) \mathrm{n}$ para cada conjunto de diques foram próximas [média $(\mathrm{La} / \mathrm{Yb}) \mathrm{n}=5,38 \pm 1,27$ ] e indicam um baixo enriquecimento de ETRL em relação aos ETRP, característico de toleitos continentais.

Os diagramas de correlação de razões de elementos incompatíveis são utilizados para caracterizar as fontes do magma e contaminação crustal. No diagrama La/Nb versus Zr/La (Fig.
15A) os diques da PL plotam principalmente no eixo E-MORB - OIB, com amostras de Camacan e Itajú do Colônia com tendência para a Crosta Superior, evidenciando possibilidade de contaminação. Os diques de Ilhéus-Olivença apresentam os maiores valores de $\mathrm{Zr} / \mathrm{La}$ aproximando-se de valores do manto primitivo, enquanto os menores valores são registrados para Salvador e Camacan. O diagrama Zr/Nb versus Zr/Y (Fig. 15B) mostra que os diques da PL são plotados na área entre os valores de E-MORB, OIB e Crosta Superior, mais próximos do E-MORB. Os valores mais altos de Zr/Y são dos corpos de Salvador e os menores para Ilhéus-Olivença.
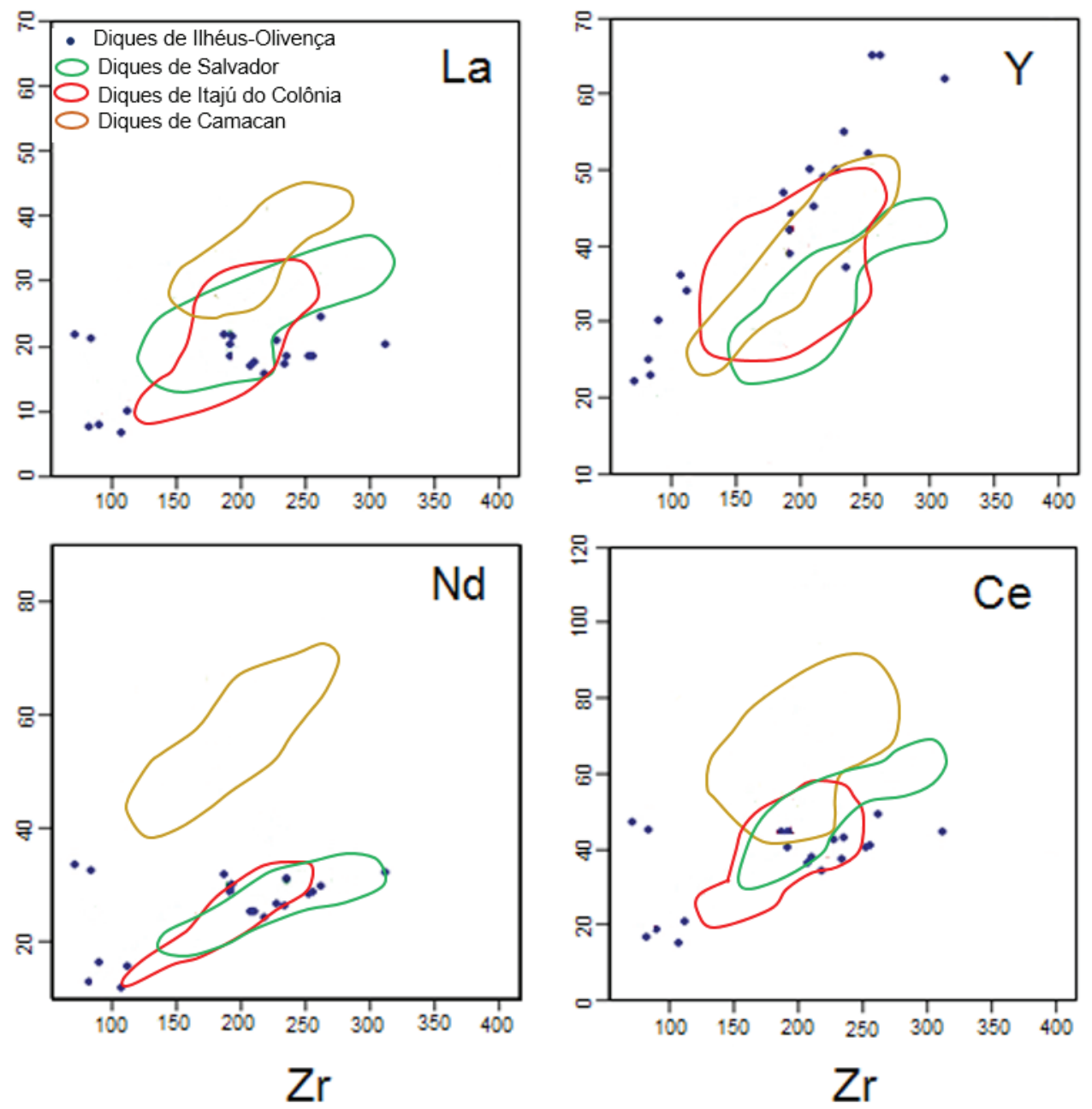

Figura 14. Diagramas binários de correlação entre $\mathrm{Zr}(\mathrm{ppm})$ versus elementos traço (ppm) para os diques máficos da Província Litorânea.

Figure 14. Correlaction binary diagrams $\mathrm{Zr}(\mathrm{ppm})$ versus trace elements (ppm) for the Coastal Province mafic dykes. 
Tabela 1. Razões de elementos terras-raras (ETR) dos diques máficos da Província Litorânea comparado com valores do Manto Primitivo (McDonough \& Sun, 1995), N-MORB, E-MORB e OIB (Sun \& McDonough, 1989).

Table 1. Rare-Earth elements ratios from Coastal Province mafic dykes compared to the values for Primitive mantle (McDonough \& Sun, 1995), N-MORB, E-MORB and OIB (Sun \& McDonough, 1989).

\begin{tabular}{ccccccccc}
\hline Razões & $\begin{array}{c}\text { Diques } \\
\text { Máficos } \\
\text { de Ilhéus- } \\
\text { Olivença }\end{array}$ & $\begin{array}{c}\text { Diques } \\
\text { Máficos } \\
\text { de }\end{array}$ & $\begin{array}{c}\text { Diques } \\
\text { Máficosador } \\
\text { de }\end{array}$ & $\begin{array}{c}\text { Diques } \\
\text { Camacan }\end{array}$ & $\begin{array}{c}\text { Máficos de } \\
\text { Itajú do } \\
\text { Colônia }\end{array}$ & $\begin{array}{c}\text { Manto } \\
\text { Primitivo }\end{array}$ & N-MORB E-MORB & OIB \\
\hline (La/Yb)n & $3,91 \pm 1,17$ & $6,41 \pm 4,87$ & $6,49 \pm 2,82$ & $4,73 \pm 2,58$ & 1,6 & 0,59 & 1,51 & 2,31 \\
$($ La/Sm)n & $1,67 \pm 0,30$ & $2,71 \pm 0,97$ & $2,50 \pm 0,93$ & $2,21 \pm 0,68$ & 1,47 & 0,82 & 2,66 & 17,13 \\
$(\mathrm{Sm} /$ Yb)n & $2,33 \pm 0,55$ & $2,24 \pm 0,53$ & $2,56 \pm 0,43$ & $2,06 \pm 0,54$ & 0,92 & 0,86 & 1,1 & 4,63 \\
\hline
\end{tabular}
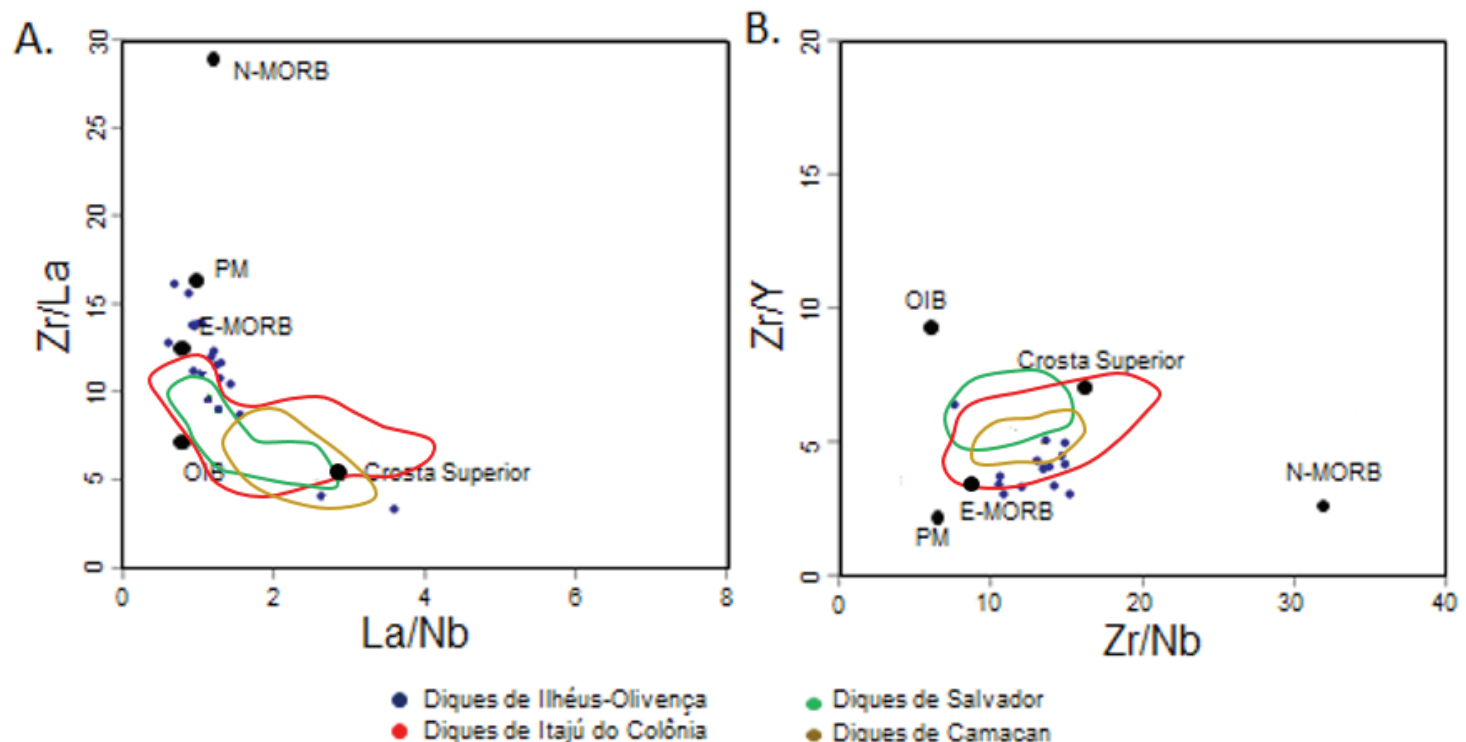

Figura 15. Diagrama de razões de elementos incompatíveis. A) La/Nb versus Zr/La; B) Zr/Nb versus Zr/Y. Crosta Superior (Condie, 1993), E-MORB, N-MORB, OIB e PM (Manto Primitivo) (McDonough \& Sun, 1995).

Figure 15. Incompatible elements ratios diagram. A. Zr/Y versus $\mathrm{Nb} / \mathrm{Y} ; \mathrm{B}$ ) $\mathrm{Zr} / \mathrm{Nb}$ versus $\mathrm{Zr} / \mathrm{Y}$. Crosta Superior (Condie, 1993), E-MORB, N-MORB, OIB e PM (Manto Primitivo) (McDonough \& Sun, 1995).

O diagrama $\mathrm{Zr} / \mathrm{Y}$ versus $\mathrm{Nb} / \mathrm{Y}$ (Fig. 16A) possibilita distinguir fontes mantélicas do tipo pluma das não-pluma e caracterizar o comportamento magmático em relação aos reservatórios mantélicos e ambientes tectônicos (Condie, 2005). Os enxames de diques da PL plotam majoritariamente no campo das rochas originadas por pluma no eixo entre o manto primitivo e as fontes enriquecidas, além de uma pequena tendência para os valores da crosta continental superior, possivelmente causado por contaminação. O enxame de Ilhéus-Olivença se aproxima mais do valor do manto primitivo, enquanto que os outros corpos filonianos plotam mais próximos das fontes enriquecidas, sendo que os corpos de Salvador apresentam os maiores valores das razões incompatíveis.

No diagrama log $\mathrm{Zr}$ versus log $\mathrm{Zr} / \mathrm{Y}$ (Fig. 16B), proposto por Sun \& McDonough (1989), os diques da PL plotam entre o OIB e E-MORB, mais próximos de fonte enriquecida, e observa-se que o padrão de distribuição das amostras sugere que tanto o processo de fusão parcial quanto cristalização fracionada atuaram na formação desses enxames. 

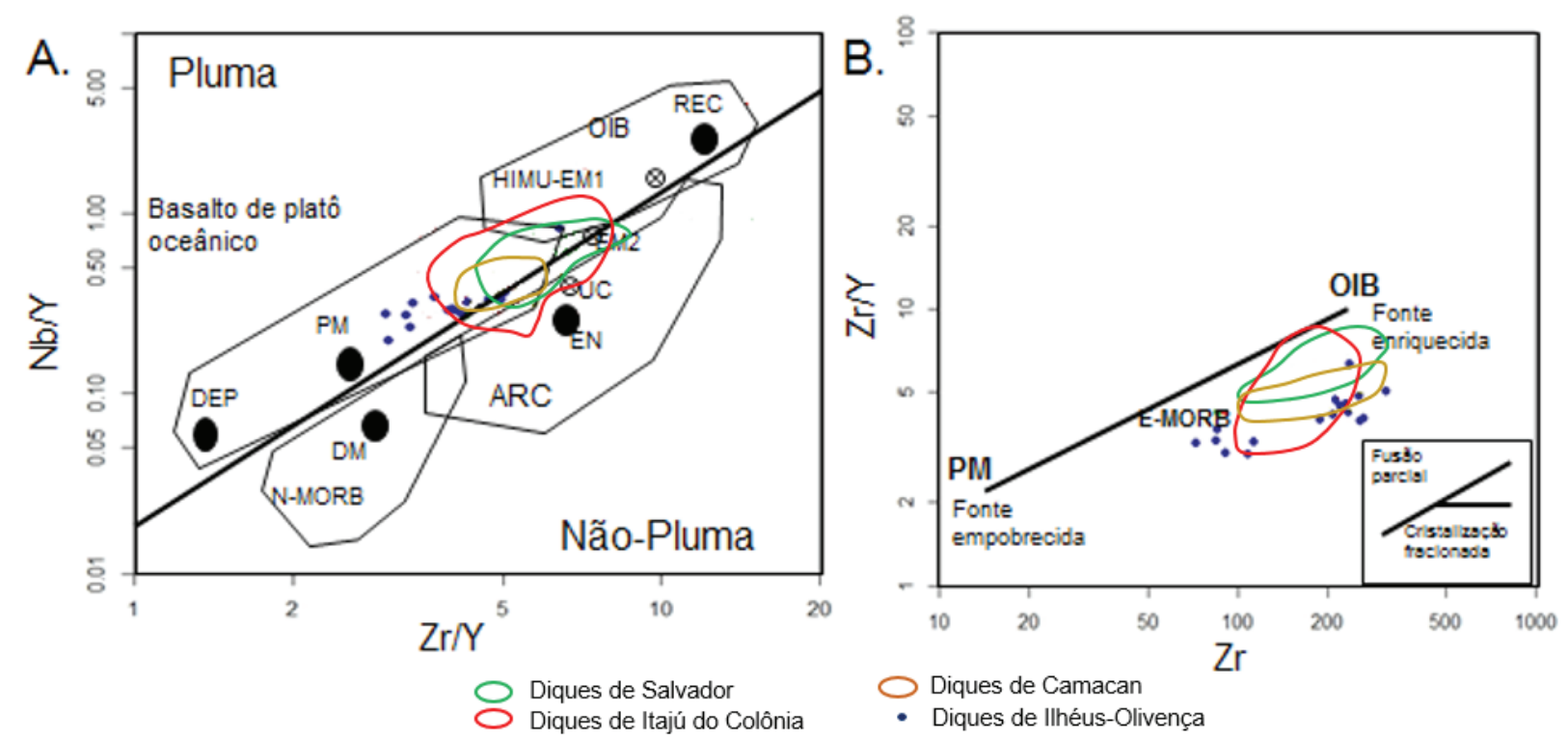

Figura 16. Diagrama de elementos incompatíveis. A) Diagrama $\mathrm{Zr} / \mathrm{Y}$ versus $\mathrm{Nb} / \mathrm{Y}$, segundo Condie (2005), com os campos para as composições de basaltos de diferentes ambientes tectônicos; B) Diagrama binário log Zr versus log Zr/Y. UCCrosta Continental Superior; PM- Manto Primitivo; DM- Manto Depletado Raso; HIMU- Fonte Alto $\mu U$ (U/Pb); EM1 e EM2Fontes Mantélicas Enriquecidas; ARC- Basaltos de Arco; N-MORB- Basaltos de Cadeia Mesoceânica; OIB- Basaltos de Ilha Oceânica; DEP- Manto Depletado Profundo; EM- Componente Enriquecido; REC- Componente Reciclado.

Figure 16. Incompatible elements diagram. A) Zr/Y versus Nb/Y diagram, according Condie (2005), with the fields for the compositions of basalts from diferent tectonic settings; B) Binary diagram log Zr versus log Zr/Y. UC- Upper Continental Crust; PM- Primitive Mantle; DM- Shallow Depleted Mantle; HIMU- High $\mu U$ Source; EM1 and EM2- Enriched Mantle Sources; ARC- Arc Basalts; N-MORB- Normal Mid Ocean Ridge Basalt; OIB- Ocean Island Basalt; DEP- Deep Depleted Mantle; EM- Enriched Component; REC-Recycled Component.

A figura 11 e tabela 2 apresentam a comparação dos elementos incompatíveis e as suas razões para diques máficos da PL e do Global Subducting Sediment (GLOSS) (Plank \& Langmuir, 1998), do Normal-Mid-Ocean Ridge Basalt (N-MORB), do Enriched-Mid-Ocean Ridge Basalt (E-MORB) (McDonough \& Sun, 1995), do Ocean Island Basalt (OIB) (Sun \& McDonough, 1989), Crosta inferior (Hacker et al., 2015), Crosta superior (Taylor \& McLennan, 1985) e Crosta continental média (Weaver, 1991). É possível observar que os valores entre os diferentes enxames são semelhantes denotando uma fonte homogênea para eles. Também é observado que as razões da Província Litorânea se assemelham aos dos reservatórios dos tipos E-MORB e OIB, porém os valores dos elementos LIL (Rb e Ba) são maiores nos corpos em estudo, possivelmente resultado da participação de crosta continental média (Tab. 2) ou de uma fonte do tipo GLOSS incorporados à fonte mantélica durante a subducção de sedimentos em crosta oceânica sob o manto litosférico que o enriquecem em fluidos ricos nesses elementos incompatíveis, embora esse último seja pouco provável, devido à grande discrepância dos valores apresentados (Tab. 2).

\section{1.2.2 Petrogênese da Província Litorânea}

A análise dos dados petrográficos e geoquímicos dos diques da Província Litorânea revelam informações importantes sobre a gênese e evolução do magmatismo, a natureza da fonte e os processos envolvidos na origem desses corpos. Essas rochas apresentam poucas variações litológicas e composicionais, sendo elas quase exclusivamente basaltos toleiíticos com valores de $\mathrm{SiO}_{2}$ variando entre 40,00 e 52,29\% (Ilhéus-Olivença: 43,5-49,95; Salvador: 43,51-52,65; Camacan: 45,23-50,64 e Itajú do Colônia: 40,00-51,68), MgO entre 3,85 e 12,07\% (Ilhéus-Olivença: 4,06-9,08; Salvador: 4,38-12,07; Camacan: 3,85-6,80 e Itajú do Colônia: 3,92-6,50) e de majoritariamente de alto titânio $\left(\mathrm{TiO}_{2}>1,5 \%\right)$. A pouca variabilidade encontrada reflete a baixa atuação de processos de diferenciação entre eles. o comportamento geoquímico de elementos maiores e os padrões de elementos incompatíveis 
Tabela 2. Valores médios de razões de elementos incompatíveis dos diques máficos estudados, do Global Subducting Sediment (GLOSS) (Plank \& Langmuir, 1998), do Normal-Mid-Ocean Ridge Basalt (N-MORB), do Enriched-Mid-Ocean Ridge Basalt (E-MORB) (McDonough \& Sun, 1995), do Ocean Island Basalt (OIB) (Sun \& McDonough, 1989), Crosta inferior (Hacker et al., 2015), Crosta Superior (Taylor \& McLennan, 1985) e Crosta Continental Média (Weaver, 1991).

Table 2. Average values of incompatible elements ratios for the Coastal Province mafic dykes compared to Global Subducting Sediment (GLOSS) (Plank \& Langmuir, 1998), Normal-Mid-Ocean Ridge Basalt (N-MORB), Enriched-MidOcean Ridge Basalt (E-MORB) (McDonough \& Sun, 1995), Ocean Island Basalt (OIB) (Sun \& McDonough, 1989) e lower crust (Hacker et al., 2015), upper crust (Taylor \& McLennan, 1985), average continental crust (Weaver, 1991).

\begin{tabular}{|c|c|c|c|c|c|c|c|c|c|c|c|}
\hline Razões & $\begin{array}{l}\text { Diques } \\
\text { Máficos } \\
\text { de Ilhéus- } \\
\text { Olivença }\end{array}$ & $\begin{array}{c}\text { Diques } \\
\text { Máficos } \\
\text { de } \\
\text { Salvador }\end{array}$ & $\begin{array}{c}\text { Diques } \\
\text { Máficos } \\
\text { de Itajú } \\
\text { do } \\
\text { Colônia }\end{array}$ & $\begin{array}{l}\text { Diques } \\
\text { Máficos } \\
\text { de } \\
\text { Camacan }\end{array}$ & GLOSS & $\begin{array}{c}\text { N- } \\
\text { MORB }\end{array}$ & $\begin{array}{c}\text { E- } \\
\text { MORB }\end{array}$ & OIB & $\begin{array}{l}\text { Crosta } \\
\text { Inferior }\end{array}$ & $\begin{array}{l}\text { Crosta } \\
\text { Superior }\end{array}$ & $\begin{array}{c}\text { Crosta } \\
\text { Continental } \\
\text { (média) }\end{array}$ \\
\hline $\mathrm{Rb} / \mathrm{Sr}$ & 0,07 & 0,07 & 0,06 & 0,07 & 0,17 & 0,01 & 0,03 & 0,05 & 0,03 & 0,32 & 0,24 \\
\hline $\mathrm{Zr} / \mathrm{Y}$ & 4,2 & 6,14 & 5,53 & 4,87 & 436 & 2,64 & 3,32 & 9,66 & 4,25 & 8,63 & 5 \\
\hline $\mathrm{Ce} / \mathrm{Y}$ & 0,91 & 1,75 & 1,37 & 1,78 & 1,92 & 0,26 & 0,68 & 2,75 & 1,25 & 2,9 & 1,81 \\
\hline $\mathrm{Ba} / \mathrm{Nb}$ & 22,48 & 24,9 & 22,01 & 17,76 & 86,8 & 2,7 & 7,12 & 7,29 & 51,8 & 22 & 54 \\
\hline $\mathrm{La} / \mathrm{Yb}$ & 5,74 & 9,42 & 6,94 & - & 10,4 & 0,82 & 2,66 & 17,1 & 5,3 & 13,63 & 8,82 \\
\hline $\mathrm{La} / \mathrm{Nb}$ & 1,29 & 1,59 & 1,69 & 2,26 & 3,2 & 1,07 & 0,76 & 0,77 & 1,6 & 1,2 & 2,2 \\
\hline $\mathrm{Ba} / \mathrm{La}$ & 18,78 & 15,82 & 14,1 & 10,54 & 26,9 & 2,52 & 9,04 & 9,46 & 32,4 & 18,33 & 25 \\
\hline $\mathrm{Zr} / \mathrm{Nb}$ & 12,64 & 11,12 & 12,92 & 12,06 & 14,5 & 31,76 & 8,79 & 5,8 & 13,6 & 7,6 & 16,2 \\
\hline $\mathrm{La} / \mathrm{Sm}$ & 2,67 & 4,32 & 3,52 & - & 5 & 0,95 & 2,42 & 3,7 & 3,07 & 6,66 & 5 \\
\hline
\end{tabular}

mostram a atuação da cristalização fracionada na evolução do magma com participação do plagioclásio e clinopiroxênio. Os dados de razões de elementos incompatíveis (Tab. 2) revelam que possivelmente o enxame de Ilhéus-Olivença é o mais primitivo entre os diques da $\mathrm{PL}$, enquanto que os de Salvador são os mais evoluídos ou a contaminação crustal foi mais presente na evolução desses corpos. Os valores de mg\# também corroboram com isso, sendo que a média para Ilhéus-Olivença é 0,28 e a maioria das amostras dos diques de Salvador apresentam mg\# abaixo de 0,20. Os enxames de Itajú do Colônia e Camacan apresentam valores de mg\# intermediários de 0,24 e 0,26, respectivamente.

A caracterização da gênese do magma que foi cristalizado para originar os diques da $\mathrm{PL}$ revela a natureza enriquecida da fonte mantélica envolvida na origem desses enxames, confirmada pelas semelhanças com E-MORB e OIB (poucas amostras dos diques de Itajú do Colônia e Salvador), o que sugere restrita e talvez local influência desse componente na origem do manto parental. O enriquecimento da fonte possivelmente se deu por sedimentos/fluidos subductados diferentes da Global Subducting Sediment (GLOSS) (Plank \& Langmuir, 1998). Sugere-se também que além de uma fonte enriquecida, os diques estudados tiveram uma participação por contaminação pela crosta, de forma diferenciada, demonstrado nos diagramas das figuras 15 e 16. Os diagramas de $\mathrm{Zr}$ versus elementos incompatíveis e o paralelismo dos padrões multielementares demonstram que a fonte é semelhante e homogênea para os quatro enxames em estudo.

\section{Conclusões}

O estudo realizado nos diques máficos de Ilhéus-Olivença, sul do Estado da Bahia, permitiu esclarecer aspectos sobre a petrologia desses corpos, a partir de dados petrográficos e geoquímicos, bem como estabelecer um estudo comparativo com os diques de Salvador, Camacan e Itajú do Colônia, pertencentes a Província Litorânea.

Podemos destacar como características principais entre os diques máficos da Província Litorânea: (i) são isotrópicos com granulação fina a média e espessuras variando de poucos centímetros a dezenas de metros, chegando no máximo a 50m; (ii) estruturas indicam que o sentido preferencial do fluxo magmático em Ilhéus-Olivença, Camacan e Itajú do Colônia foi de leste para oeste, enquanto que em Salvador foi de sul para norte; (ii) microscopicamente evidenciam uma assembleia mineralógica constituída essencialmente por plagioclásio (andesina) e augita; (iv) são basaltos em ambiente 
intraplaca com afinidade toleítica, sendo que os diques de Ilhéus-Olivença apresentam características mais primitivas, enquanto os de Salvador mais evoluídas, todos com plagioclásio e piroxênio como fases minerais fracionadas durante a cristalização; (v) o padrão de ETR normalizado para manto primitivo e as razões de ETR mostraram um leve enriquecimento em ETRL em relação aos ETRP, característico de toleítos continentais; (vi) o comportamento dos elementos traço revelou uma distribuição espacial semelhante e o paralelismo entre os padrões dos diferentes conjuntos evidenciou uma fonte única para essas rochas, com características entre E-MORB e OIB, no qual possivelmente o processo de contaminação pela crosta continental foi importante e diferencial, necessitando entretanto, de dados isotópicos para confırmação e; (vii) após a integração dos dados geocronológicos e geoquímicos sugere-se que esses diques máficos fazem parte da expressão superficial na forma de hotspot de um mesmo evento geotectônico meso/neoproterozoico de ascensão de pluma mantélica.

Agradecimentos. Agradecemos a Fundação de Amparo à Pesquisa do Estado da Bahia (FAPESB) pelo apoio através da concessão de bolsa do primeiro autor e apoio financeiro (Processos CNPq 47690187/2013-8, FAPESB 0030/2016). Os autores também agradecem aos revisores da Revista Pesquisas em Geociências as valiosas contribuições ao trabalho.

\section{Referências}

Barbosa, J.S.F. \& Sabaté, P. 2003. Colagem paleoproterozoica de placas arqueanas do Cráton do São Francisco na Bahia. Revista Brasileira de Geociências, 33(1): p.7-14.

Chaves, A.O., Ernst, R.E., Söderlund, U., Wang, X. \& Naeraa, T. 2018. The 920-900 Ma BahiaGangila lip of the São Francisco and Congo cratons and link with Dashigou-Chulan lip of North China craton: New insights from $\mathrm{U}-\mathrm{Pb}$ geochronology and geochemistry. Precambrian Research, 329: 124-137.

CBPM. Companhia Baiana de Pesquisa Mineral. CPRM. Companhia de Pesquisa de Recursos
Minerais. 2006. Mapa Geológico da Bahia. Salvador. Escala 1:100000.

Corrêa Gomes, L. C.; Tanner de Oliveira, M. A. F.; Motta, A. C.; Cruz, M. J. M. 1996. Província de diques máficos do Estado da Bahia: Mapa, estágio atual do conhecimento e evolução temporal. Superintendência de Geologia e Recursos Minerais, Salvador. 144 p.

Corrêa-Gomes, L.C. 2000. Diques Máficos: Uma reflexão teórica sobre o tema e seu uso no entendimento prático da Geodinâmica Fissural. Exemplos de Salvador e IlhéusOlivença, Zona Costeira Atlântica do Estado da Bahia - Brasil. Salvador. 196p. Dissertação de Mestrado, Programa de Pós-graduação em Geologia, Instituto de Geociências, Universidade Federal da Bahia.

Condie, K.C. 1993. Chemical composition and evolution of the upper continental crust: Contrasting results from surface samples and shales. Chemical Geology, 104(1/4): 1-37.

Condie, K.C. 2005. High field strength element ratios in Archean basalts: a window to evolving sources of mantle plumes? Lithos, 79(3/4): 491-504.

Cruz, L.A. 2013. Aspectos de campo, petrografia e geoquímica preliminar dos diques máficos das praias Jardim de Alah, Paciência e Ondina, Salvador - BA. Salvador. 73p. Monografia de conclusão de curso, curso de Geologia, Instituto de Geociências, Universidade Federal da Bahia.

D'Agrella Filho, M.S., Pacca, I.G., Onstott, T.C., Renne,P.R\&Teixeira,W. 1989. Paleomagnetism and geochronology of mafic dikes from the regions of Salvador, Olivença and Uauá, São Francisco Craton, Brazil. Boletim IG-USP. Série Científica, 20: 1-8.

Evans, D.A.D., Trindade, R.I.F., Catelani, E.L.D, D'Agrella Filho, M.S., Heaman, L.M., Oliveira, E.P. \& Salminen, J.M. 2015. Return to Rodinia? Moderate to high palaeolatitude of the São Francisco/Congo craton at 920 Ma. Geological Society, Special Publications, 424(1): 167-190. Hacker, B.R., Kelemen, P.B. \& Behn, M.D. 2015. Continental lower crust. Annual Review of Earth Planet Science, 43: 167- 205.

Irvine, T.N. \& Baragar, W.R.A. 1971. A guide to the chemical classification of common rocks. 
Canadian Journal Earth Science, 8: 523-548. Janoušek, V., Farrow, C.M., Erban, V. \& Trubač, J. 2006. Brand new Geochemical Data Toolkit (GCDkit 3.0) - is it worth upgrading and browsing documentation? (Yes!). Geologicke vyzkumy na Morave a ve Slezsku, 18: 26-30

Le Bas, M.J., Le Maitre, R.W., Streckeisen, A. \& Zanettin, B. 1986. A chemical classification of Volcanic Rocks based on the Total Alkali-Silica Diagram. Journal of Petrology, 27(3): 745-750.

McDonough, W.F. \& Sun, S.S. 1995. The composition of the Earth. Chemical Geology, 120: 223-253

Menezes Leal, A.B., Corrêa-Gomes, L.C. \& Guimarães, J.T. 2012. Diques máficos. In: Barbosa, J.S.F. (Coordenação geral). Geologia da Bahia. Pesquisa e Atualização. Volume 2. Salvador, CBPM, p. 199-231

Moraes Brito, C. 1992. Caracterização geológica, geoquímica e petrográfica dos diques máficos proterozóicos da região de Salvador-BA. São Paulo. 153p. Dissertação de Mestrado, Programa de Pós-Graduação em Geoquímica e Geotectônica, Instituto de Geociências, Universidade de São Paulo.

Pearce, J.A. \& Norry, M.J. 1979. Petrogenetic implications of $\mathrm{Ti}, \mathrm{Zr}, \mathrm{Y}$ and $\mathrm{Nb}$ variations in volcanic rocks. Contributions to Mineralogy and Petrology, 69: 33- 47.

Pinheiro Amorim, A.C. 2017. Petrologia dos enxames de diques máficos ectasiano de Itajú do Colônia e criogeniano de Itapé, sudeste do estado da Bahia. Salvador. 228p. Tese de Doutorado, Programa de Pós-Graduação em Geologia, Instituto de Geociências, Universidade Federal da Bahia.

Plank, T. \& Langmuir, C.H. 1998. The chemical composition of subducting sediment and its consequences for crust and mantle. Chemical Geology, 145(3/4): 325-394.

Renne, P.R., Onstott, T.C., D'Agrella Filho, M.S., Pacca, I.G. \& Teixeira, W. 1990. Ar ${ }^{40} / \mathrm{Ar}^{39}$ dating of $1.0-1.1 \mathrm{Ga}$ Magnetizations from the São Francisco and Kalahari Cratons: Tectonic Implications for Pan-African and Brasilian Mobile Belts. Earth and Planetary Science Letters, 101(2/4): 349-366.
Santos, M.C.P. 2010. Caracterização Petrográfica e Geoquímica Preliminar dos diques máficos da região de Camacan, Bahia, Brasil. Salvador. 124p. Monografia de Conclusão de Curso. Curso de Geologia, Instituto de Geociências, Universidade Federal da Bahia.

Silva, S.O. 2018. Caracterização petrológica dos diques máficos da orla de Salvador, Bahia. Salvador. 54p. Dissertação de Mestrado, Programa de Pós-Graduação em Geologia, Instituto de Geociências, Universidade Federal da Bahia.

Souza, J.S. 2013. Geologia, metamorfismo e geocronologia de litotipos de Salvador-Bahia. Salvador. 125p. Tese de Doutorado, Programa de Pós-Graduação em Geologia, Instituto de Geociências, Universidade Federal da Bahia.

Takahashi, E. \& Kushiro, I. 1983. Melting of a dry peridotite at high pressures and basalt magma genesis. American Mineralogist, 68 (9/10): 859-879.

Sun, S.-S. \& McDonough, W.F. 1989. Chemical and isotopic systematic of oceanic basalts: implications for mantle composition and processes. In: Saunders, A.D. \& Norry, M.J. (Eds.). Magmatism in the Ocean Basins. Geological Society, 42(1), 313-345.

Tanner de Oliveira, M.A.F. 1989. O enxame de diques máficos de Olivença: Aspectos geoquímico e petrogenéticos. São Paulo. 154p. Tese de Doutorado, Programa de PósGraduação em Geoquímica e Geotectônica, Instituto de Geociências, Universidade de São Paulo.

Taylor, S.R. \& McLennan. 1985. The continental crust: Its composition and evolution. Oxford: Blackwell Scientific, $311 p$.

Vieira, K.C. 2016. Diques máficos de Camacan, sul do estado da Bahia: uma caracterização petrológica. Salvador. 88p. Monografia de Conclusão de Curso. Curso de Geologia, Instituto de Geociências, Universidade Federal da Bahia

Weaver, B.L. 1991. The origin of ocean island. Basalt end-member compositions: trace element and isotopic constraints. Earth and Planetary Science Letters, 104(2/4): 381-397. 